\title{
The nematode homologue of Mediator complex subunit 28, F28F8.5, is a critical regulator of $C$. elegans development.
}

\author{
Markéta Kostrouchová ${ }^{1,2}$ ， David Kostrouch ${ }^{3}$, Ahmed A Chughtai ${ }^{3}$, Filip Kaššák ${ }^{3}$, Jan P. Novotný ${ }^{3}$, Veronika \\ Kostrouchová ${ }^{3}$, Aleš Benda ${ }^{4}$, Michael W. Krause ${ }^{5}$, Vladimír Saudek ${ }^{6}$, Marta Kostrouchová ${ }^{3}$, Zdenek \\ Kostrouch Corresp. 3 \\ 1 Biocev, First Faculty of Medicine, Charles University, Prague, Czech Republic \\ 2 Department of Pathology, Third Faculty of Medicine, Charles University, Prague, Czech Republic \\ 3 Biocev, First Faculty of Medicine, Charles University in Prague, Prague, Czech Republic \\ 4 Imaging Methods Core Facility, BIOCEV, Faculty of Science, Charles University, Prague, Czech Republic \\ 5 Laboratory of Molecular Biology, National Institute of Diabetes and Digestive and Kidney Diseases, National Institutes of Health, Bethesda, Maryland, \\ USA \\ 6 Metabolic Research Laboratories, Wellcome Trust-Medical Research Council Institute of Metabolic Science, University of Cambridge, Cambridge, United \\ Kingdom
}

Corresponding Author: Zdenek Kostrouch

Email address: Zdenek.kostrouch@lf1.cuni.cz

The evolutionarily conserved Mediator complex is a critical player in regulating transcription. Comprised of approximately two dozen proteins, the Mediator integrates diverse regulatory signals through direct protein-protein interactions that, in turn, modulate the influence of Mediator on RNA Polymerase II activity. One Mediator subunit, MED28, is known to interact with cytoplasmic structural proteins, providing a potential direct link between cytoplasmic dynamics and the control of gene transcription. Although identified in many animals and plants, MED28 is not present in yeast; no bona fide MED28 has been described previously in C. elegans. Here, we identify bioinformatically F28F8.5, an uncharacterized predicted protein, as the nematode homologue of MED28. As in other Metazoa, F28F8.5 has dual nuclear and cytoplasmic localization and plays critical roles in the regulation of development. F28F8.5 is a vital gene and its null mutants have severely malformed gonads and do not reproduce. F28F8.5 interacts on the protein level with the Mediator subunits MDT-6 and MDT-30. Our results indicate that F28F8.5 is an orthologue of MED28 and suggest that the potential to link cytoplasmic and nuclear events is conserved between MED28 vertebrate and nematode orthologues. 
1 The nematode homologue of Mediator complex subunit 28, F28F8.5, is a

2 critical regulator of C. elegans development.

3

4 Markéta Kostrouchová ${ }^{1,2}$, David Kostrouch ${ }^{1}$, Ahmed A. Chughtai ${ }^{1}$, Filip Kaššák ${ }^{1}$, Jan Philipp

5 Novotný $^{1}$, Veronika Kostrouchová ${ }^{1}$, Aleš Benda ${ }^{3}$, Michael W. Krause ${ }^{4}$, Vladimír Saudek ${ }^{5}$, Marta

6 Kostrouchová $^{1}$ and Zdeněk Kostrouch ${ }^{1}$ *

7

101 Biocev, First Faculty of Medicine, Charles University, Průmyslová 595, 25242 Vestec, Czech

11 Republic

12 Department of Pathology, Third Faculty of Medicine, Charles University, Ruská 87, 10000 Praha

13 10, Czech Republic

143 Imaging Methods Core Facility, BIOCEV, Faculty of Science, Charles University, Prague,

15 Czech Republic

164 Laboratory of Molecular Biology, National Institute of Diabetes and Digestive and Kidney

17 Diseases, National Institutes of Health, Bethesda, Maryland, USA

185 University of Cambridge Metabolic Research Laboratories, Wellcome Trust-Medical Research

19 Council, Institute of Metabolic Science, Cambridge CB2 0QQ, United Kingdom

$21 *$ Corresponding author

$22{ }^{*}$ Corresponding author for bioinformatics 
$24 *$ Corresponding author:

25

26

27

28

29

30

31

32

33

34

35

36 Short title: MED28 homologue in C. elegans.

\section{ABSTRACT}

38 The evolutionarily conserved Mediator complex is a critical player in regulating transcription.

39 Comprised of approximately two dozen proteins, the Mediator integrates diverse regulatory signals

40 through direct protein-protein interactions that, in turn, modulate the influence of Mediator on

41 RNA Polymerase II activity. One Mediator subunit, MED28, is known to interact with

42 cytoplasmic structural proteins, providing a potential direct link between cytoplasmic dynamics

43 and the control of gene transcription. Although identified in many animals and plants, MED28 is

44 not present in yeast; no bona fide MED28 has been described previously in C. elegans. Here, we

45 identify bioinformatically F28F8.5, an uncharacterized predicted protein, as the nematode

46 homologue of MED28. As in other Metazoa, F28F8.5 has dual nuclear and cytoplasmic 
47 localization and plays critical roles in the regulation of development. F28F8.5 is a vital gene and 48 its null mutants have severely malformed gonads and do not reproduce. F28F8.5 interacts on the

49 protein level with the Mediator subunits MDT-6 and MDT-30. Our results indicate that F28F8.5

50 is an orthologue of MED28 and suggest that the potential to link cytoplasmic and nuclear events

51 is conserved between MED28 vertebrate and nematode orthologues.

52

53

54

55

Abbreviations: $F 28 F 8.5^{* *}$ - gene coding for protein F28F8.5, F28F8.5a - splice form a, F28F8.5a - protein form a, F28F8.5b - splice form b, F28F8.5b - protein form b, gDNA genomic DNA, $P_{F 28 F 8.5}(V: 15573749):: g f p:: F 28 F 8.5$ - edited $F 28 F 8.5$ with $g f p$ tagged to the $\mathrm{N}-$ terminus in the position $V: 15573749$ (allele named edited $g f p:: F 28 F 8.5$ ), $P_{F 28 F 8.5}$ $(V: 15573749): \because g f p::$ let858(stop)::SEC::F28F8.5 - edited F28F8.5 disrupted by $g f p$ and SEC (self-excising cassette) (allele named edited disrupted F28F8.5), $P_{F 28 F 8.5(400 b p)}: \because F 28 F 8.5: \because g f p$ F28F8.5 tagged with GFP on its C-terminus regulated by its predicted internal promoter with the size of 400 bp upstream of the ATG, GFP::F28F8.5 - protein F28F8.5 tagged on its N-terminus with GFP, F28F8.5::GFP - protein F28F8.5 tagged on its C-terminus with GFP, MED28 vertebrate Mediator complex subunit 28 gene, MED28 - vertebrate Mediator complex subunit 28 protein, Med28 - Mediator complex subunit 28 in a general sense; this nomenclature is also used in Drosophila and mouse gene nomenclature.

** Note: F28F8.5 is now renamed with WormBase approval to $m d t-28$. 
70 INTRODUCTION

71

72

73

The Mediator complex is a multiprotein assembly that is capable of integrating cellular signals with the regulation of transcription through direct interaction with RNA Polymerase II. The Mediator complex is found in all eukaryotic organisms. The core Mediator complex is comprised of 21 protein subunits in yeast and a similar number (26) in mammals, all named MED followed by a unique numerical designation (Poss et al. 2013; Allen \& Taatjes 2015). In addition to this core Mediator complex, four additional subunits comprising the CDK-8 or kinase module can associate with the core (Poss et al. 2013). The Mediator complex likely co-evolved with basal transcription factors with a level of conservation between different phyla that is relatively low (Poss et al. 2013; Allen \& Taatjes 2015). While most Mediator subunits are present in similar molar ratios and comprise the core complex, some subunits were found to be present in variable amounts when complexes were isolated from tissue culture cells (Kulak et al. 2014). Quantification of proteomically analyzed Mediator subunits showed that distinct forms of the complex have variable transcriptional activity (Paoletti et al. 2006) and analysis of Mediator complex subunits in Drosophila indicated that some subunits are critical only for specific gene transcription from endogenous genes but not for transcription from synthetic promoters (Kim et al. 2004). This diversity of Mediator subunit function reflects distinct transcription factor interactions with Mediator components and with Pol II, greatly expanding its possible regulatory roles for Mediator. For example, some Mediator subunits are essential for the transcription of many different protein-coding genes, while other subunits are essential for only a subset of genes, translating cellular signaling pathways to the regulation of specific target gene sets (reviewed in (Grants et al. 2015)). 
One of the Mediator complex subunits, MED28, is only found in higher eukaryotes.

$94 M E D 28$ was originally identified as a gene expressed in endothelial cells where it was named EG-1

95 (Endothelial-derived Gene-1) (Liu et al. 2002); it was later shown to be part of the Mediator

96 complex and re-named MED28 (Sato et al. 2004; Beyer et al. 2007). In addition to its role in the

97 Mediator complex, the MED28 subunit has several cytoplasmic-associated interactions. MED28

98 has been shown to associate with 1) the actin cytoskeleton and linked to the regulation of smooth

99 muscle genes (Wiederhold et al. 2004), 2) several Src-family kinases and it is a target of their

100 phosphorylation (Lee et al. 2006), and 3) the plasma membrane where it interacts with Grb2 and

101 Merlin (also called Neurofibromin 2 or Schwannomin) (Wiederhold et al. 2004), membrane-

102 cytoskeleton scaffolding proteins linking actin filaments to the cell membrane (McClatchey \&

103 Giovannini 2005; McClatchey \& Fehon 2009). These many and diverse cytoplasmic interactions

104 suggest that MED28 could function to transmit cytoskeletal signals to transcription in the nucleus

105 (Lee et al. 2006).

106 Although conserved between insects and mammals, a bona fide MED28 homologue had

107 yet to be identified in nematodes. The relatively low conservation of Mediator complex subunits

108 between eukaryotic phyla (Poss et al. 2013; Allen \& Taatjes 2015) makes the identification of

109 orthologues in distant species difficult and some suggested orthologues may require re-

110 classification. Our previous work showed that the protein previously identified as "MDT-28"

111 (Mediator-28) in nematodes (Bourbon 2008) is instead the nematode homologue of perilipin, a

112 protein regulating lipid metabolism at the level of lipid droplets and is not related to MED28

113 (Chughtai et al. 2015). Thinking it was unlikely that a MED28 homologue would be absent in

114 nematode genomes, we searched for it using conserved features of MED28 orthologues from

115 various phyla. Herein we identify a previously uncharacterized protein, F28F8.5, as the closest 
116 MED28 homologue. We show that F28F8.5 localizes to both nuclear and cytoplasmic

117 compartments in most, if not all, cells throughout development. Down-regulation by RNAi, or

118 disruption of $F 28 F 8.5$ by deletion, results in multiple developmental defects during embryonic

119 and larval development. Our work indicates that the homologue of Mediator complex subunit 28

120 exists in nematodes and suggests that the potential to link cytoplasmic and nuclear events is

121 conserved between vertebrate and nematode MED28 homologues.

122

123 MATERIALS AND METHODS

\section{Sequence analysis}

The UniProtKB (uniprot.org) and NCBI (ncbi.nlm.nih.gov) databases were searched with BLAST, PSI-BLAST (Altschul et al. 1997), HHblits (Remmert et al. 2011) and HHpred (Soding et al. 2005) programs. The protein sequences were identified with their UniProtKB identifiers and the nucleotide sequences with their NCBI ones. The sequences were aligned with T-coffee (Notredame et al. 2000; Di Tommaso et al. 2011) and PROMALS (Pei \& Grishin 2007; Pei et al. 2007; Pei et al. 2008). The secondary structure predictions were performed with PSIPRED (Jones

131 1999; Cuff \& Barton 2000; McGuffin et al. 2000). Multiple sequence alignments were displayed 132 and analyzed with Jalview (Clamp et al. 2004).

\section{RNA isolation and cDNA synthesis}

RNA and cDNA were prepared as described (Zima et al. 2015) with modifications.

136 Cultured nematodes were collected in water and pelleted by centrifugation for 5 min at $200 \mathrm{xg}$ and

$1374{ }^{\circ} \mathrm{C}$. The excess of water was removed and the pellet was frozen at $-80{ }^{\circ} \mathrm{C}$. For the isolation of 138 RNA, the pellet was quickly melted and dissolved in $300 \mu \mathrm{l}$ of resuspension buffer $(10 \mathrm{mM}$ Tris- 
$139 \mathrm{HCl} ; 10 \mathrm{mM}$ EDTA, 5\% 2- mercaptoethanol; 0.5\% SDS; pH 7.5). After adding $8 \mu$ of proteinase

$140 \mathrm{~K}(20 \mathrm{mg} / \mathrm{ml})$, the sample was mixed and incubated $1 \mathrm{~h}$ at $55^{\circ} \mathrm{C}$. RNA was isolated by phenol-

141 chloroform extraction and ethanol precipitation. The obtained RNA was incubated with RQ1

142 DNase (Promega, Fitchburg, WI, USA) and purified again by phenol-chloroform extraction and

143 ethanol precipitation. Complementary DNA (cDNA) was prepared with SuperScript III

144 (Invitrogen, Carlsbad, CA, USA) using random hexamers.

145

146 Strains, transgenic lines and genome editing

147 The C. elegans Bristol N2 strain was used whenever not specifically stated and maintained

148 as described (Brenner 1974).

149 KV3: (8418) - heterozygous animals carrying one edited disrupted allele of $F 28 F 8.5\left(P_{F 28 F 8.5}\right.$

150 (V:15573749)::gfp::let858(stop)::SEC::F28F8.5 - edited F28F8.5 disrupted by gfp and SEC) and

151 one WT allele of F28F8.5. This line segregates mutant animals.

152 KV4: (8419) - edited F28F8.5 carrying $g f p: \because F 28 F 8.5$ in its normal genomic position $153\left(P_{F 28 F 8.5}(V: 15573749): \because g f p: \because F 28 F 8.5\right.$ on both alleles.

154

155 Preparation of $P_{F 28 F 8.5(400 b p)}: \because F 28 F 8.5:: g f p$

$156 \quad$ For preparation of transgenic lines encoding F28F8.5::GFP from extrachromosomal arrays

157 under regulation of endogenous promoter, we used the PCR fusion-based technique

158 (Hobert 2002). Primers 7886 and 7888 were used for amplification of the genomic sequence of

$159 F 28 F 8.5$ (consisting of approximately $400 \mathrm{bp}$ of the predicted promoter region preceding the

160 coding region of $F 28 F 8.5$ ). The gene encoding GFP was amplified from the pPD95.75 vector with

161 primers 6232 and 6233. The complete construct was amplified with primers 7887 and 6234. The 
162 resulting fusion construct contains the 3' UTR from pPD95.75 (originally from the unc-54 gene).

163 The PCR mixture was injected into the gonads of young adult hermaphrodite animals together

164 with marker plasmid pRF4. The sequences of all primers used in the paper are in supplementary

165 information.

166

\section{Genome editing}

168 Lines with edited genomes were prepared from wild type N2 animals using the

169 CRISPR/Cas9 system as described (Dickinson et al. 2013; Dickinson et al. 2015; Ward 2015;

170 Dickinson \& Goldstein 2016). Using this strategy, the F28F8.5 gene was edited by insertion of a

171 construct including the coding sequence of GFP and a self-excising cassette (SEC) containing the

172 sqt-1(d) gene (a visible selection marker leading to a Rol phenotype), hs::Cre (heat shock inducible

173 Cre recombinase) and hygR (hygromycin resistance) genes. The sgRNA sequence was targeted

174 near the start of the coding sequence for the F28F8.5 gene using a modified pJW1219 plasmid

175 (Addgene, Cambridge, MA, USA) as the Cas9 vector (pMA007); it was prepared by PCR with

176 primers $8403 \mathrm{~A}$ and 8333 and used in a concentration of $50 \mathrm{ng} / \mu \mathrm{l}$ for microinjections. The plasmid

177 pMA007 was co-injected with the rescue repair template plasmid based upon modified pDD282

178 vector (pMA006) in a concentration of $10 \mathrm{ng} / \mu \mathrm{l}$ and with 3 markers (see below). The repair

179 template plasmid pMA006 was prepared in two steps. First the plasmid pMA005 was prepared

180 from gDNA of $F 28 F 8.5$ (containing both repair arms) and amplified by PCR with primers 8404

181 and 8405 and cloned into pCU19 backbone. The plasmid pMA005 was subsequently modified -

182 the FP-SEC segment was added and the CRISPR/Cas9 site was altered to protect against Cas9

183 attack. The linear PCR product of pMA005 was prepared using primers 8406 and 8407 with

184 overlapping regions for Gibson assembly (New England BioLabs, Ipswich, MA, USA). The 
185 primer 8406 was prepared with alternate codons for protection against CRISPR/Cas9 site. Linear

186 insert of FP-SEC was prepared by PCR from pDD282 plasmid (Addgene, Cambridge, MA, USA)

187 with primers 8408 and 8409. Primers were prepared with overlapping parts for cloning into linear

188 pMA005 plasmid by Gibson assembly and the final rescue plasmid pMA006 was prepared.

189 Plasmids pGH8 (10 ng/ $\mu \mathrm{l})$, pCFJ104 (5 ng/ $\mu \mathrm{l})$ and pCFJ90 (2.5 ng/ $\mu \mathrm{l})$ (Addgene, Cambridge, MA,

190 USA) were used as fluorescent co-injection markers. After microinjections the population of

191 nematodes were grown for 3 days at $25^{\circ} \mathrm{C}$ and hygromycin (Invitrogen) was added in a final

192 concentration of $250 \mu \mathrm{g} / \mathrm{ml}$. After 3 days integrated nematodes were selected according to the

193 rolling phenotype and loss of extrachromosomal arrays.

194 Using this strategy, we obtained a heterozygous line (KV3) with a disrupted F28F8.5 gene

195 with an inserted $g f p$ regulated by the endogenous promoter of $F 28 F 8.5$ in one allele and one WT

196 allele. This line segregated homozygous animals for $P_{F 28 F 8.5}: F 28 F 8.5: \because g f p$ (edited F28F8.5 with

197 SEC $-P_{F 28 F 8.5}(V: 15573749):: g f p:: l e t 858($ stop $)::$ SEC::F28F8.5) with disrupted F28F8.5 on both

198 alleles and expressing GFP under the regulation of the endogenous promoter). Animals of this line

199 were clearly distinguishable by their developmental phenotypes, weak expression of GFP in the

200 cytoplasm and the presence of rol marker. These animals were sterile and had severe

201 developmental defects (see results). The genotypes were confirmed by single worm PCR of

202 representative animals after their microscopic analysis (with primers 8398 and 8414).

203 The excision of the self-excising cassette was achieved by a 4 hour heat shock at $34^{\circ} \mathrm{C}$.

204 The line KV4 was obtained: animals with both alleles carrying the edited $F 28 F 8.5$ gene in the 205 form of $g f p: \because F 28 F 8.5$ in its normal genomic position (edited F28F8.5 with $g f p$ tagged to the $\mathrm{N}-$ 206 terminus $\left.-P_{F 28 F 8.5}(V: 15573749): \because g f p:: F 28 F 8.5\right)$. 
209 and 8456. PCR was done by REDTaq ReadyMix PCR reaction (Sigma-Aldrich, St. Louis,

210 Missouri, USA) or by Phusion High-Fidelity DNA Polymerase (New England Biolabs, Ipswich,

211 MA, USA). During the maintenance of the heterozygous line KV3, animals with one edited

212 disrupted $F 28 F 8.5$ allele and one allele with edited $F 28 F 8.5$ after self-excision of SEC were also

213 generated (recognizable by the Rol phenotype, expression of $g f p$ in nuclei and lack of

214 developmental phenotypes). Schemes for genome editing are accessible in Supplementary files

215 S4, S5, S6 and S7.

216

217 Down-regulation of gene expression by RNA interference

For RNAi done by microinjections, F28F8.5 cDNA was prepared from total cDNA using

219 primers 7889 and 7890. The plasmid pPCRII(Topo) (Invitrogen, Carlsbad, Ca, USA) containing

$220 F 28 F 8.5 b$ cDNA was linearized using restriction enzymes NotI/ SacI. The dsRNA was prepared

221 by in vitro transcription using SP6/T7 Riboprobe ${ }^{\circledR}$ in vitro Transcription Systems (Promega,

222 Madison, WI, USA) from opposing promoters synthesizing complementary single stranded RNA

223 (ssRNA) for both strands of F28F8.5 cDNA and its complementary strand. After in vitro

224 transcription ( $\sim 2$ hours) equal volumes of sense and antisense RNA were mixed, incubated at 75

$225{ }^{\circ} \mathrm{C}$ for $10 \mathrm{~min}$ and slowly cooled to room temperature during $30 \mathrm{~min}$. Control RNAi was prepared

226 from the promoter region of $n h r-60$ as previously described (Simeckova et al. 2007) and repeated

227 with dsRNA prepared using the vector L4440. Vectors used for preparation of dsRNA were

228 linearized and transcribed using T7 RNA polymerase. The dsRNA concentration was measured 
229 using a UV spectrophotometer and diluted to the concentration of $\sim 2 \mu \mathrm{g} / \mu \mathrm{l}$ that was used for

230 injections (Tabara et al. 1999; Timmons et al. 2001; Vohanka et al. 2010).

231

\section{Microinjections}

Microinjections of plasmids, DNA amplicons or dsRNA into gonads of young adult

234 hermaphrodites were done using an Olympus IX70 microscope equipped with a Narishige

235 microinjection system (Olympus, Tokyo, Japan). The plasmids were injected into the gonads of

236 young adult hermaphrodites as described (Tabara et al. 1999; Timmons et al. 2001; Vohanka et al. 237 2010).

238

\section{Microscopy}

Fluorescence microscopy and Nomarski optics microscopy were done using an Olympus

241 BX60 microscope equipped with DP30BW CD camera (Olympus, Tokyo, Japan). Animals were

242 analyzed on microscopic glass slides with a thin layer of $2 \%$ agarose and immobilized by $1 \mathrm{mM}$

243 levamisole (Sigma-Aldrich, St. Louis, MO, USA). Confocal microscopy of live homozygous

244 animals with edited $F 28 F 8.5$ expressing $g f p:: F 28 F 8.5$ was performed using an inverted Leica

245 SP8 TCS SMD FLIM system equipped with a 63x 1.2 NA water immersion objective, a pulsed

246 white light laser (470-670 nm), AOBS and two internal hybrid single photon counting detectors,

247 and operated by Leica Application Suite X program (Leica Microsystems, Wetzlar, Germany).

248 The GFP fluorescence was excited at a wavelength of $488 \mathrm{~nm}$ and the emitted light was

249 simultaneously recorded in two spectral ranges (Channel $1-495 \mathrm{~nm}$ to $525 \mathrm{~nm}$, Channel $2-525$

$250 \mathrm{~nm}$ to $580 \mathrm{~nm}$; the two channel setup was used to help resolve between spectrally different

251 autofluorescence and GFP fluorescence signals). 


\section{Fluorescence-lifetime imaging microscopy (FLIM)}

254 For FLIM acquisitions the single photon counting signal from the internal hybrid detectors, 255 acquired during confocal acquisitions, was simultaneously processed by HydraHarp400 TCSPC 256 electronics (PicoQuant, Berlin, Germany) and information about the arrival times of all photons 257 was stored to a hard-drive in TTTR data format. TTTR is freely accessible at 258 (https://www.picoquant.com/images/uploads/page/files/14528/technote_tttr.pdf). Data structure, 259 program description and user instructions are also freely accessible at 260 https://github.com/PicoQuant/PicoQuant-Time-Tagged-File-Format-

261 Demos/blob/master/PTU/Matlab/Read_PTU.m). The signal from both time synchronized 262 channels was added up. The false color scale (1 to $3 \mathrm{~ns}$ ) is based on the average photon arrival 263 time, with blue color representing short lifetime and red color long lifetime fluorescence.

Single nematode PCR

266 Single animal PCR was used for verification of all transgenic lines. Following the microscopy 267 examination, selected animals were removed from microscopic slides and transferred into caps of 268 PCR tubes with $4 \mu$ l of solution of Proteinase K $(20 \mathrm{mg} / \mathrm{ml})$ diluted 1:333 in Barstead Buffer 269 (resulting in Barstead Lysis Buffer which consists of $50 \mathrm{mM} \mathrm{KCl,} 10 \mathrm{mM}$ Tris pH 8.3, $2.5 \mathrm{mM}$ $270 \mathrm{MgCl}_{2}, 0.45 \%(\mathrm{v} / \mathrm{v}) \mathrm{NP} 40$ (Nonidet P-40), 0.45\% (v/v) Tween-20, 0.01\% (w/v)). Proteinase K was

271 diluted immediately before use as a $20 \mathrm{mg} / \mathrm{ml}$ stock solution which was kept on ice and diluted to 272 final working solution at a concentration of $200 \mu \mathrm{g} / \mathrm{ml}$. The tube was sealed in bottom-up position 273 and the sample transferred to the bottom of the tube by centrifugation. The tube was frozen for 10 $274 \min$. at $-70^{\circ} \mathrm{C}$. Next, the tube was heated for 1 hour at $65^{\circ} \mathrm{C}$ and additional $15 \mathrm{~min}$. at $95^{\circ} \mathrm{C}$. The 
275 resulting sample was used immediately for amplification of DNA by PCR or stored at $-80^{\circ} \mathrm{C}$ before

276 further analysis. Similarly, genomic DNA was prepared from selected nematode culture plates

277 and used for further screening by PCR and sequencing.

278 The resulting precipitated DNA was dissolved in $10 \mu \mathrm{l}$ of deionized water and used for 279 amplification by PCR using primers outside the edited genomic regions. Specificity of 280 amplification was confirmed by DNA sequencing.

281 Similarly, homozygous animals with edited $F 28 F 8.5$ (with $g f p$ inserted in front of the 282 F28F8.5 START codon) were analyzed by single worm PCR with primers 7887 (sense primer) 283 and 7890 or 8454 (antisense primers).

284

\section{Quantitative RT-PCR}

286 For quantitative RT-PCR, the technique described by Ly et al. (Ly et al. 2015) was used with 287 modifications. For assessment of the level of expression of $F 28 F 8.5$ from homozygous animals with the edited disrupted gene, 5 adult homozygous mutant animals recognized by the phenotype 289 and the same number of young WT hermaphrodites with minimum number of formed embryos were manually harvested and collected in separate Eppendorf tubes. Reverse transcription was done using the Maxima H Minus cDNA synthesis kit (Thermo Fischer, Waltham, MAs, USA) as recommended by manufacturer. Universal probe library and primers designed with the help of

293 ProbeFinder Assay Design Software were used and qPCR was run on LightCycler 2.0 purchased 294 from Roche (Roche, s.r.o. Prague, Czech Republic). An average of 3 sample cDNAs and 3 control 295 cDNAs were analyzed (twice in duplicates and one time as single experiments), all containing the 296 same amount of RNA for RT for each experiment. The expression of $F 28 F 8.5$ was normalized to 
$297 a m a-1$ and the values obtained in homozygous mutant animals with disrupted $F 28 F 8.5$ gene were

298 compared to values obtained in control WT N2 animals.

299

\section{Binding studies}

301 Binding studies were done as described (Kostrouch et al. 2014) with modifications. The coding

302 region of $m d t-6$ was amplified using primers 8292 and 8293 from cDNA prepared from mixed

303 stages C. elegans cultures and cloned into pTNT vector ((Promega, Madison, WI, USA, amplified

304 with primers 8277 and 8278) using the Quick Ligation Kit (New England Biolabs, Ipswich, MA,

305 USA) and expressed in the rabbit reticulocyte TNT-system (Promega, Madison, WI, USA). The

306 in vitro transcribed protein was labeled using ${ }^{35} \mathrm{~S}$ Methionine (Institute of Isotopes, Budapest,

307 Hungary). F28F8.5 coding sequence (amplified using 8255 and 8256 primers with 15 bp overhangs

308 for insertion into the vector) was cloned into pGEX-2T vector ((Amersham Pharmacia Biotech,

309 Amsterdam, UK), amplified with primers 8253 and 8254)) using the GeneArt Seamless PLUS

310 Cloning and Assembly Kit (Thermo Fisher Scientific, Waltham, MA, USA), transformed into

311 BL21 E. coli cells and the production of protein was induced by isopropyl $\beta$-D-1-

312 thiogalactopyranoside (IPTG) (Sigma-Aldrich, St. Louis, MO, USA). The Mediator subunit MDT-

31330 was amplified from mixed stages C. elegans cDNA with sense primer 8302 and reverse primer

3148527 (containing FLAG sequence), cloned into pET28a $(+)$ vector ((Addgene, Cambridge, MA,

315 USA), amplified with primers 8519 and 8520) using the Quick Ligation Kit (New England

316 Biolabs), transformed into BL21 E. coli cells and induced by IPTG. The lysate from bacteria

317 producing His $_{6}$-MDT-30-FLAG was used directly or purified on HiTrap Chelating HP column

318 (GE Healthcare, Chicago, IL, USA). Proteins produced by the TNT system or bacterial lysates of

319 bacteria transformed with FLAG labeled Mediator subunits were incubated with glutathione- 
320 agarose (Sigma-Aldrich, St. Louis, MO, USA) adsorbed with equal amounts of GST or GST-

321 F28F8.5. Radioactively labeled proteins were detected using TRI-CARB 1600TR, Liquid

322 Scintillation Analyzer (Packard, Meriden, CT, USA).

323 The resulting samples (labeled proteins bound to GST- or GST-F28F8.5) were separated by

324 polyacrylamide gel electrophoresis. ${ }^{35}$ S-MDT-6 was visualized by autoradiography and

325 subsequently, the gel containing radioactively labeled protein was localized using superimposed

326 autoradiograms, excised and the radioactivity determined in the scintillation detector. FLAG-

327 labeled MDT-30 was determined by Western blot using an anti-FLAG antibody (monoclonal anti-

328 FLAG, M2 (Sigma-Aldrich)) and quantified densitometrically by ImageJ computer program

329 (https://imagej.nih.gov/ij/download.html) (Schneider et al. 2012).

332 RESULTS

333 Identification of the closest homologue of vertebrate Mediator complex subunit

33428 in C. elegans

335

To identify the $C$. elegans homologue of MED28, we queried protein databases with curated SwissProt sequences from UniProtKB. They comprised several mammalian and insect proteins (e.g. human MED28_HUMAN and D. melanogaster MED28_DROME). The more sensitive profile-to-profile HHblitz and HHpred algorithms provided hits to a C. elegans annotated protein F28F8.5a and b with highly significant E-values. According to Wormbase (WS248), two protein isoforms are produced from the $F 28 F 8.5$ gene, isoform a with the length of 200 amino

341 acids and isoform $\mathrm{b}$ that has a two amino acid insertion at position 20 of the N-terminal 342 evolutionarily non-conserved region. The best results were obtained when pre-aligned vertebrate 
343 and insect MED28 homologues were used as query in 3 iterations $\left(\mathrm{E}<10^{-48}\right.$ and the probability of

344 true positive $>99.99 \%$ ). When the pre-aligned nematode sequences homologous to F28F8.5 were

345 used to query profiles of human or Drosophila sequences in reciprocal searches, MED28 proteins

346 were obtained with equally significant scores. BLAST and PSI-BLAST searches in their standard

347 settings were not able to reveal a significant hit $\left(\mathrm{E}<10^{-3}\right)$; the only nematode hit was a Trichinella

348 spiralis protein (E5RZQ1). However, when the searches in protein databases were limited to

349 sequences from Ecdysozoa with Insecta excluded (conservative inclusion threshold $\mathrm{E}<10^{-6}$ ) in the

350 first two iterations and then continued in the complete data database of sequences from all species

351 in the subsequent iterations, the final hits of F28F8.5 included human and Drosophila MED28.

352 PSI-BLAST with $T$. spiralis query sequence in database limited to Ecdysozoa in the first two

353 iterations provided both human and Drosophila MED28 and F28F8.5 in one run $\left(\mathrm{E}<10^{-8}\right)$. We

354 concluded from these searches that F28F8.5 is a homologue of MED28 and very likely its

355 previously unrecognized orthologue.

356

All PSI-BLAST MED28 homologues possess variable N- and C-termini of 3 to 80 amino

357 acids showing no conservation across Metazoa. This conservation is loose even just within

358 Drosophilae or Caenorhabditae sequences. Only the central core of about 110 amino acids is

359 preserved in metazoan evolution. Fig. 1 shows a sequence alignment of this conserved core of

360 selected MED28 homologues. All sequences are predicted to fold into three helices forming a

361 putative coiled coil fold (UniProt annotation). Submitting the alignment shown in Fig. 1 to HHpred

362 for 3D structure recognition reveals a structural fold of yeast MED21 (PDB identifier 1ykh_B). It

363 is indeed a 3-helix coiled coil forming a heterodimer with MED7. It can be expected that MED28

364 forms a very similar fold interacting with a yet to be determined subunit of the MED complex.

\section{$365 \quad \mathbf{F 2 8 F 8 . 5}$ is a nuclear as well as a cytoplasmic protein}


367 both an individual and multigene transcript, located as the last gene in a four gene operon that is

368 both SL-1 and SL-2 trans-spliced. To determine the intracellular localization of F28F8.5, we

369 edited the F28F8.5 gene using CRISPR/Cas9 technology. We inserted the gene coding for GFP

370 directly in front of the first codon. The arrangement used in our experiment (based on (Dickinson

371 et al. 2013; Dickinson et al. 2015; Ward 2015; Dickinson \& Goldstein 2016)) employed a self-

372 excising cassette that was added after $g f p$. This strategy initially created a disrupted $F 28 F 8.5$ gene

373 and putative null allele that can be detected by expression of GFP alone regulated by the

374 endogenous promoter elements of $F 28 F 8.5$. We found that only heterozygous animals could be

375 propagated due to the sterility of homozygotes tagged in this manner. Assuming this tag is not

376 deleterious to the expression of other genes in the operon, this result suggests that $F 28 F 8.5$ is an 377 essential gene.

378 After removal of the self-excising cassette from this edited $F 28 F 8.5$ gene induced by heat

379 shock (visualized by continuous expression of GFP::F28F8.5 fusion protein and loss of the Rol

380 phenotypic marker), the endogenous locus had an N-terminus GFP-tagged F28F8.5 gene that we

381 maintained as homozygous animals, demonstrating this edited allele is fully functional. Note that

382 both known protein isoforms of F28F8.5 ( $\mathrm{a}$ and $\mathrm{b}$ ) would be tagged on their N-terminus with GFP 383 by this method.

384 The GFP::F28F8.5 pattern was ubiquitous, both nuclear and cytoplasmic from embryos to 385 adults (Fig. 2). Prominent nuclear localization was found in oocytes, zygotes, larvae, and adults.

386 Cells with clear nuclear accumulation of GFP::F28F8.5 included epidermal, intestinal, pharyngeal,

387 uterine and vulval muscle cells (Fig. 2). The gonad expressed $g f p:: F 28 F 8.5$ and mitotic as well 388 as meiotic nuclei accumulated GFP::F28F8.5 protein (Fig. 2). 
390 distribution of GFP::F28F8.5. S canning through several focal planes revealed signal in the GFP

391 excitation/emission range in nuclei as well as in the cytoplasm of embryos, all larval stages and

392 adults (Fig. 3). Structures resembling gut granules were also strongly positive in the GFP

393 recording mode. In order to distinguish between GFP-specific fluorescence and autofluorescence,

394 we applied FLIM with an expectation that autofluorescence (such as that from gut granules) is

395 likely to produce a signal with a short fluorescence lifetime opposed to GFP-specific fluorescence.

396 Structures such as gut granules were clearly detected (Fig. 3, panels O, Q, S, T and U, blue color)

397 while fluorescence with a longer lifetime expected for GFP::F28F8.5 was detected in the germline,

398 in oocytes and embryos and in most somatic nuclei of larvae as well as adult animals (Fig. 3,

399 panels $\mathrm{O}, \mathrm{Q}, \mathrm{S}, \mathrm{T}$ and $\mathrm{U}$, red and yellow colors).

$400 \quad$ We also generated transgenic lines encoding F28F8.5::GFP from extrachromosomal arrays

401 consisting of endogenous internal $F 28 F 8.5$ promoter regulating a fusion gene with $g f p$ attached to

402 F28F8.5 on its C-terminal end. As with the N-terminally tagged F28F8.5, F28F8.5::GFP showed

403 both nuclear and cytoplasmic localization. As expected for an extrachromosomal transgene, the

404 expression of F28F8.5::gfp was not detected in the germline. This reporter was expressed in

405 embryos starting at the 2-fold stage and continued throughout development (Supplementary Fig.

406 S1). We did notice that F28F8.5::gfp was expressed in the excretory cell and its channels

407 (Supplementary Fig. S1 M, N, P and Q), a pattern not observed with the endogenously edited 408 GFP-tagged gene.

409

410 F28F8.5 regulates development 
411 To achieve loss-of-function, RNAi was used to down-regulate F28F8.5 expression.

412 Analysis of 2567 progeny of 17 young adult hermaphrodites inhibited for F28F8.5 function by

413 microinjection of dsRNA into the syncytial gonad revealed that F28F8.5 is essential for proper

414 development (Fig. 4). From the total progeny, 1127 animals were affected (44\%) exhibiting

415 embryonic and larval arrest and a range of less severe phenotypes, including defective molting,

416 protruding vulvae that often burst, male tail ray defects (Fig. 4), and uncoordinated (Unc)

417 movement. In contrast with this, control young adult N2 hermaphrodites injected with control

418 dsRNA showed embryonic arrest in less than $2 \%$ of progeny (7 hermaphrodites injected, total

419 progeny observed 1066, embryonic arrest found in 19 embryos).

420 Complete loss of F28F8.5 that occurred in homozygous animals with both edited disrupted

421 alleles of the F28F8.5 gene (that are found among the progeny of heterozygous animals carrying

422 one edited disrupted allele and one WT allele) resulted in defective development that was most

423 pronounced in late larval stages. The phenotypes included a Dpy phenotype (Fig. 5C), irregular

424 gut, severely defective growth of the gonad with signs of defect in directional growth (Fig. 5 E and

$425 \mathrm{M}$ ) and Pvul phenotype (Fig $5 \mathrm{~K}$ and L). Most animals had darker gut cells than controls of the

426 same age. The gonad did not develop fully in most animals (Fig. $5 \mathrm{C}$ to L) and often contained

427 empty spaces that were prevalent in some animals leading to the formation of larvae with optically

428 thin, empty-like tissue in the position of the gonad. The gonads contained foci of irregular tissue

429 with an uncharacteristic appearance. Tissue defects were also visible in extragonadal locations,

430 especially in the place of excretory channels. Body defects were also observed in the position of

431 the uterus that was not properly formed and the spermatheca that was not identifiable in a large

432 proportion of animals. 
434 from maternal load or from SEC self-excision (Dickinson et al. 2015)) from three experiments 435 indicated that mutants with disrupted F28F8.5 had the level of expression about 17 times lower 436 compared to the levels found in WT controls (Supplementary file S8).

437 Heterozygous hermaphrodites carrying one edited disrupted allele of $F 28 F 8.5$ and one WT 438 allele were grossly normal and produced viable embryos. Unlike in homozygous animals carrying 439 the excised SEC allele, the GFP fluorescence was mostly cytoplasmic and most nuclei were not 440 showing accumulation of GFP. In some embryos, however, the nuclei accumulated GFP 441 indicating probable spontaneous SEC self-excision (Fig. 6). Analysis of progeny of the heterozygous strain KV3 revealed differences compared to the expected Mendelian segregation of phenotypes. Animals with one edited disrupted F28F8.5 allele 444 and one edited F28F8.5 allele with excised SEC were detected. They were recognizable by the Rol phenotype, expression of GFP in nuclei and lack of developmental phenotypes. This genotype was supported by PCR amplification of genomic regions from single nematodes and obtained pattern of amplified DNA fragments. These lines were not stable and were not preserved.

\section{F28F8.5 interacts with Mediator complex subunits}

To determine if F28F8.5 could be part of the Mediator complex in C. elegans, we explored its ability to interact with previously identified Mediator subunits. We expressed ${ }^{35}$ S-labeled MDT-6, part of the "head" module where MED28 is located, in rabbit reticulocyte lysate and assayed its binding to bacterially expressed GST-F28F8.5 or to GST only. As shown in Fig 7A and 7B, a strong interaction ( 7.7-fold enrichment) was detected between MDT-6 to F28F8.5 that 
456 exceeded that seen with GST alone. We also assayed for interaction between GST-F28F8.5 and

457 MDT-30, but we were unable to obtain a satisfactory ${ }^{35}$ S-Methionine labeled protein in the rabbit

458 reticulocyte system. Therefore, we expressed MDT-30 containing a FLAG sequence inserted at

459 the $\mathrm{C}$-terminus and $\mathrm{a} \mathrm{His}_{6}$ sequence positioned at the $\mathrm{N}$-terminus. After expression in bacteria and

460 purification on a nickel column, we found that the MDT-30-FLAG bound F28F8.5 preferentially

461 ( 2.5-fold enrichment) in comparison to GST alone, as revealed by Western blot using anti-FLAG

462 antibody (Fig. $7 \mathrm{C}$ and D).

\section{DISCUSSION}

In this work, we identified an uncharacterized predicted protein F28F8.5 as the likely nematode homologue of MED28. This is supported by our findings that F28F8.5 interacts with nematode homologues of MED6 and MED30 (MDT-6, and MDT-30), the close sequence

467 similarity of F28F8.5 to MED28 detected informatically in nematode genomes, a conserved dual nuclear and cytoplasmic expression pattern, and its involvement in a wide range of developmental processes. Thus we suggest F28F8.5 be identified as MDT-28, with the original gene for MDT28 now recognized as the nematode homologue of perilipin, now named PLIN-1 (Chughtai et al. 2015).

The Mediator complex as a multiprotein structure is able to interact with a large number of additional proteins and integrate regulatory signals from several cell signaling cascades (Allen \&

474 Taatjes 2015). The Mediator complex possesses a high degree of structural flexibility and variable

475 subunit composition (reviewed in (Poss et al. 2013)). In yeast, a set of core subunits is important 476 for a wide range of gene transcription (e.g. Med 17 and Med 22 (Thompson \& Young 1995;

477 Holstege et al. 1998)), while others are non-essential in terms that single mutants can be maintained 478 at laboratory conditions (Med1, Med2, Med3, Med5, Med9, Med15, Med16, Med18, Med19, 
479 Med20, Med31, and CDK module subunits Med12 (srb8), Med13 (srb9), srb10 (CDK8), and srb11

480 (CycC) (Dettmann et al. 2010)). Med31 and Srb9/Med13 Mediator subunits have different roles

481 in gene selective transcription in Saccharomyces cervisiae and in Candida albicans (Uwamahoro

482 et al. 2012). Mass spectrometry analyses indicate that many Mediator subunits are present in

483 stoichiometric quantities but some subunits are over- or under-represented in budding and fission

484 yeast and human HeLa cells (Kulak et al. 2014). Isolation of mammalian Mediator complexes

485 lacking one or more of the 26 core subunits was reported for Med1(TRAP220) (Malik et al. 2004)

486 and Med1 (Med220) and Med26 (a.k.a. Med70 or CRSP70, or ARC70) (Taatjes \& Tjian 2004)

487 (reviewed in (Allen \& Taatjes 2015), the unified nomenclature can be found in (Bourbon et al.

488 2004) and for Med70 in (Rachez \& Freedman 2001)). While in cells with a stem cell like character

489 a broad spectrum of Mediator subunits was detected, during differentiation the expression of some

490 Mediator subunits is markedly decreased (MED14, MED18, MED12, cdk8, MED26 in myotubes

491 versus myoblasts) (Deato et al. 2008). In hepatocytes MED1, MED6, MED7, MED12, MED14,

492 MED16, MED18, MED23, and CDK18 are decreased or even undetectable upon differentiation

493 from hepatoblasts to hepatocytes (D'Alessio et al. 2011). Quantitative mass spectrometry analyses

494 of Mediator complexes isolated by immunoprecipitation using four different Mediator subunits

495 expressed as FLAG-tagged proteins in HeLa cells (Med10, Med26, Med28, Med29) identified

496 most subunits of the Mediator complex in similar quantities with the exception of MED30, which

497 was found in elevated ratios by Med28 pulldown experiments compared to other tested subunits.

498 Med26 and Med29 precipitated more abundantly in their own pull-downs. Med31 was

499 immunoprecipitated more efficiently in complexes with Med10 and Med25 was the least abundant

500 subunit in all examined pull-downs (Paoletti et al. 2006). In-keeping with this, the copy numbers

501 of individual Mediator subunits identified by quantitative proteomics indicate that some subunits 
502 are in similar copy numbers while others are under-represented or more numerous in yeast as well

503 as in HeLa cells (Kulak et al. 2014). This suggests that Mediator complexes with specialized

504 functions are likely to exist. A similar situation may be observed on ribosomes. Although the

505 structure of ribosomal subunits is very firm and is given by the secondary structure of ribosomal

506 RNAs and the presence of ribosomal proteins (Ban et al. 2000; Schluenzen et al. 2000; Wimberly

507 et al. 2000), ribosome function during translation of mRNAs can be effectively regulated by viral

508 proteins (Diaz et al. 1993; Diaz et al. 1996) which reveals the existence of a regulable "ribosomal

509 code". The regulation of ribosome biogenesis and translation through the p53 pathway and

510 methylation of ribosomal RNA by fibrillarin is leading to cancer specific ribosomes (Marcel et al.

511 2013). Cells infected with the viral oncogene v-erbA, the viral form of thyroid hormone receptor

512 alpha, produce ribosomes with decreased levels of RPL11 which are translating more effectively

513 Hsp70, a protein critical for tumorigenesis in avian erythroblastosis (Nguyen-Lefebvre et al. 2014).

514 In comparison to ribosomal subunits, the Mediator complex possesses some analogies and 515 differences.

516 The unit that is forming the structural backbone of Mediator is MED14 which is critical for

517 both basal and activated transcription (Cevher et al. 2014). Mediator complexes bound to specific

518 transcription factors (SREB Mediator, VP16-Mediator, TR-Mediator, VDR-Mediator, p53-

519 Mediator) and the unliganded Mediator assume all distinct sterical conformations with

520 fundamentally altered exposed protein surfaces (Poss et al. 2013), that can be expected to form a

521 multipotent basis for additional protein-protein interactions. This is possible because the

522 fundamental features of the Mediator subunits are their intrinsically disordered regions that are to

523 a certain degree positionally conserved between species, while others evolved in a phylum or

524 species specific way (Nagulapalli et al. 2016). In yeast, Med3 and Med15 form amyloid-like 
525 protein aggregates under $\mathrm{H}_{2} \mathrm{O}_{2}$ stress conditions. The amyloid formation can be induced by

526 overexpression of Med3 or glutamine-rich domain of Med15. This subsequently leads to the loss

527 of Med15 module from Mediator and a change in the stress response (Zhu et al. 2015). The

528 Mediator complexes contact a wide range of transcription factors using a fuzzy protein interface

529 (Brzovic et al. 2011; Warfield et al. 2014). It can be therefore anticipated that additional proteins

530 with a similar protein-protein interaction potential have the capability to interact with Mediator

531 subunits if they are translocated into the nucleus.

532 Although individual Mediator complex subunits were shown to be associated with specific

533 functions (reviewed in (Grants et al. 2015)), the function of the nematode orthologue of MED28

534 could not be studied since it was not yet identified. MED28 has a special position in-between

535 Mediator subunit proteins for its dual regulatory role, one as a Mediator subunit (Sato et al. 2004;

536 Beyer et al. 2007) and the second, which is cytoplasmic, at the level of the cytoskeleton

537 (Wiederhold et al. 2004; Lee et al. 2006; Lu et al. 2006; Huang et al. 2012). It can be anticipated

538 that the interaction of primarily cytoplasmic proteins with MED28 if translocated to the nucleus

539 may be able to bring cytoplasmic regulatory interactions towards the regulation of gene expression.

540 In-between cytoplasmic proteins regulating gene expression, probably the most studied is beta-

541 catenin, an adaptor of interaction between the cytoskeleton and cell adhesion molecules which

542 critically regulates gene expression in the Wnt pathway. This connection is known in C. elegans

543 to great detail (reviewed in (Grants et al. 2015)). Interestingly, the phenotypes that we observed

544 in F28F8.5 knock-down and loss of function experiments overlap with the EGFR regulatory

545 cascade in C. elegans, especially the developmental defects of the vulva and of male specific

546 structures, most obviously, male rays (Grants et al. 2015; Grants et al. 2016). Our observation of

547 the expression of $F 28 F 8.5$ in male rays and the defective development of male specific structures 
548 after F28F8.5 RNAi support the cytoplasmic role of F28F8.5, that is in mammals mediated by

549 Grb2 (Wiederhold et al. 2004). This cytoplasmic function of F28F8.5 is supported by the known

550 involvement of the nematode homologue of Grb2, SEM-5, in the regulation of development of

551 male rays. F28F8.5 protein contains a predicted $\mathrm{SH} 2$ binding site for Grb2 in the loop positioned

552 in-between the two helices of F28F8.5, similarly as MED28 (identified using the site prediction

553 tool Motif Scan http://scansite.mit.edu/motifscan_seq.phtml) (Wiederhold et al. 2004). Although,

554 it has to be stressed that there are no close structures availabe for a high-probability prediction of

555 the structure of F28F8.5. The burst through vulva phenotype is also likely to be connected to LET-

556 60/Ras signalling (Ecsedi et al. 2015) that also supports the conservation of the dual, nuclear and

557 cytoplasmic functions, of MED28 homologues throughout the evolution of Metazoa.

558 We propose that MED28 is a candidate Mediator complex subunit linking cytoplasmic

559 structural signals towards the core of transcription regulation. The connection between

560 cytoplasmic events and regulation of gene expression can be seen frequently. Numerous

561 transcription factors are regulated by their spatial restriction, binding or incorporation into

562 cytoplasmic structures and organelles. Many proteins that have primarily cytoplasmic structural

563 functions were shown to possess transcription regulating activity (e.g. proteins interacting with

564 steroid receptors (George et al. 2009), FOX transcription factors (Gan et al. 2005; Wang et al.

565 2015), and BIR-1/Survivin (Kostrouch et al. 2014)). In-between interactions of MDT-28 that we

566 identified, the interaction with MDT-30 may suggest an additional link towards connection of

567 structural signals with the regulation of gene expression. MED30 was shown to be pulled down

568 by MDT28 quantitatively with higher efficiency compared to other subunits, possibly suggesting

569 that these two subunits may be present in some subpopulations of Mediator complexes that could

570 lack other Mediator subunits. MED30 is similarly as MED28 a likely more recent Mediator subunit 
571 specific to Metazoa and absent in yeast and it is intriguing to speculate that the more recently

572 evolved Mediator subunits are linked with the evolution of structurally differentiated cells and

573 tissues. It can be anticipated that impairment of cellular structure sensing could be involved in

574 cancer biology. In-keeping with this, MED30 was recently identified as an upregulated gene in

575 stomach cancer connected with cancer proliferative properties (Lee et al. 2015) and in

576 development of cardiomyopathy in mice carrying a missense mutation in the first exon (Krebs et

577 al. 2011). MED28 was also connected with cancer behavior and migration of cancer cells (Huang

578 et al. 2012; Huang et al. 2017). Wormbase also lists phenotypes similar to F28F8.5 knock-down

579 by RNAi for $m d t-30$, namely a dumpy phenotype (Dpy), burst through vulva and locomotion

580 defect but not a germline defect (Wormbase WS, accessed on March 11, 2017). The gene $m d t-30$

581 is organized in an operon together with F44B9.8 which is an ortholog of human RFC5 (replication

582 factor C subunit 5) and its inhibition by RNAi leads to embryonic defects. Similarly as F28F8.5,

$583 m d t-30$ is likely to be expressed independently from the operon since it is trans-spliced with both

584 SL1 and SL2 splice leaders (Wormbase WS, accessed on March 11, 2017).

585 Our results demonstrated phenotypic differences comparing knock down versus knockout 586 of F28F8.5 activity. For example, down-regulation of $F 28 F 8.5$ by RNAi resulted in embryonic

587 lethality and larval arrest whereas null mutants with a disrupted $F 28 F 8.5$ gene found in the progeny

588 of heterozygous animals with one edited disrupted allele and one WT allele or one edited disrupted

589 allele and one edited allele coding for GFP::F28F8.5 were able to reach adulthood. Morevoer,

590 most phenotypes that we observed in our RNAi experiments have previously been reported in

591 Wormbase (WS254) based on high throughput screens (Kamath \& Ahringer 2003; Simmer et al.

592 2003; Frand et al. 2005; Sonnichsen et al. 2005). One explanation of the differences between

593 knockdowns versus knockouts it that heterozygous animals with one functional allele of $F 28 F 8.5$ 
594 supply their embryos with maternal transcripts, while the embryos in the progeny of parents with

595 F28F8.5 down-regulated by RNAi are devoid of this maternal load; maternal rescue of loss-of-

596 function mutations is frequently observed in C. elegans early development. This model further

597 predicts that the amount of $F 28 F 8.5$ product inherited maternally is not sufficient for normal

598 development of the gonad and other post-embryonic developmental events such as male tail

599 development. Alternatively, our F28F8.5 disruptions could be affecting other genes in the operon,

600 although none have been reported to result in high level embryonic lethality when eliminated

601 individually. The three other genes within this operon are $a t x-3$, the orthologue of human ataxin-

602 3, F28F8.9, a non-characteristic predicted protein and F28F8.7, an orthologue of human

603 ELMSAN1 (ELM2 and Myb/SANT domain containing 1) and TRERF1 (transcriptional regulating

604 factor 1). RNAi experiments have been reported for atx-3 and F28F8.9, of which only inhibition

605 of atx-3 produced embryonic arrest in $10 \%$ to $25 \%$ of embryos. This suggests that even if our gene

606 disruption is affecting other genes in the operon (as reported in (Bosher et al. 1999)), the severe

607 larval changes reported here are most likely the consequence of inhibition of $F 28 F 8.5$. In addition,

608 F28F8.5 is also expressed independently from its own promoter based on our translational fusions

609 and reported SL1 splice leader (Mounsey et al. 2002; Matus et al. 2010). Further studies will be

610 required to sort out the potentially complex interactions among these genes in development.

611 The broad expression pattern and indispensability of F28F8.5 we find during embryonic

612 development is similar to findings reported for Med28 in other systems (Li et al. 2015); Mouse

613 Genome Database (http:/www.mousephenotype.org/data/genes/MGI:1914249)(Eppig et al.

614 2015); Human Protein Atlas (http://www.proteinatlas.org)(Uhlen et al. 2015). F28F8.5 was also

615 shown to have tissue-specific functions, as in the anchor cell where it is important for the regulation 
616 of anchor cell translocation across the basement membrane during the formation of the developing

617 vulva (Matus et al. 2010).

618 Our experiments with transgenes fused to GFP also show the differences between the 619 expression of $\mathrm{N}$ - or C- terminally labeled F28F8.5. The expression of fusion transgenes is not 620 entirely without functional and developmental consequences. N-terminally labeled F28F8.5 is 621 likely to be able to maintain the nuclear functions of F28F8.5. It is also able to support, at least 622 partially the cytoplasmic functions of F28F8.5 in male rays, since they are formed but are not 623 entirely normal and defects in some animals were observed. It seems likely that GFP-labeled 624 subunits in viable lines may help localize the place of action of labeled proteins as well as their 625 function in C. elegans. We did not observe elevated cytoplasmic expression of GFP::F28F8.5 in 626 the anchor cell described by Matus and colleagues (Matus et al. 2010). This is probably dependent 627 on the position of GFP in the fusion protein which was on the C-terminus, in the case of the study 628 by Matus et al. as well as in the case of the data reported by Wormbase (both based on a clone 629 originally prepared by Ian Hope (Matus et al. 2010)). It has been suggested that proteins containing $630 \mathrm{GFP}$ at their C-terminus are more frequently properly intracellularly localized compared to 631 proteins containing GFP at their N-terminus (Palmer \& Freeman 2004). GFP positioned at the N632 terminus might also fold differently and fail to produce fluorescence in oxidizing compartments 633 (Aronson et al. 2011).

634 The direct link between effector proteins and the regulation of transcription can be traced 635 to Eubacteria and Archaea. Lrp /AsnC proteins, metabolic effectors in Archaea and related Lrs14 636 proteins are serving as multipotent (Lrp) and specific (Asn) regulators of gene expression. Lrs14 637 has a clear negative autoregulatory potential illustrating the ancient origin of the transcriptional 638 function of effector proteins (Bell \& Jackson 2000; Thaw et al. 2006; Orell et al. 2013). 
639 Similarities between the core transcriptional machinery of Eukaryotes and Archaea can be clearly

640 found (Hirata \& Murakami 2009). While the archaeal transcriptional complex seems to be

641 sufficiently dependent on two basal transcriptional regulators, TBP and TFB, Pol II dependent

642 transcription, in higher eukaryotes requires 5 or 6 general transcription factors (reviewed in

643 (Burton et al. 2016)) and the modular assembly of the Mediator complex at the promoters of

644 regulated genes. This modular complex is capable of linking the informatic network necessary for

645 cells differentiated to multiple cell types (or in other words multiple structural cell states) with

646 gene expression. MED28 homologues are thus likely to be able to bring cytoplasmic proteins to

647 the core of gene transcription. This may explain why MED28 evolved in multicellular eukaryotes 648 containing structurally differentiated cells.

649 In conclusion, MED28 homologues in vertebrates, insects and nematodes share similarities 650 indicating their conserved roles in cytoplasmic and nuclear events. It can be hypothesized that 651 many proteins that are primarily building blocks of cellular structures and structure-associated 652 proteins are likely to be part of regulatory loops that regulate gene expression. Similarly, as is the 653 case of evolution of operons in Rhabditida that are formed during evolution if they are biologically 654 tolerated for the sake of other regulatory or energetic gains (Qian \& Zhang 2008; Blumenthal 655 2012), regulation by structural proteins may also be evolving for a limited number of structural 656 proteins leaving other structure-forming proteins available for evolution of other functions. The 657 homologues of MED28 in mammals, insects and nematodes therefore may be a link between 658 cellular structural states and regulation of gene expression.

659

660

661 ACKNOWLEDGEMENTS 
662 The authors thank WormBase and NCBI for accessibility of data and bioinformatics support and 663 Caenorhabditis Genetics Center CGC, which is funded by NIH Office of research Infrastructure 664 Programs (P40 OD010440) for the N2 wild type strain.

665

666

667

\section{REFERENCES}

668

669

670

671

672

673

674

675

676

677

678

679

680

681

682

683

684

685

686

687

688

689

690

691

692

693

694

695

696

697

698

699

700

701
Allen BL, and Taatjes DJ. 2015. The Mediator complex: a central integrator of transcription. Nat Rev Mol Cell Biol 16:155-166.

Altschul SF, Madden TL, Schaffer AA, Zhang J, Zhang Z, Miller W, and Lipman DJ. 1997. Gapped BLAST and PSI-BLAST: a new generation of protein database search programs. Nucleic Acids Res 25:3389-3402.

Aronson DE, Costantini LM, and Snapp EL. 2011. Superfolder GFP is fluorescent in oxidizing environments when targeted via the Sec translocon. Traffic 12:543-548. 10.1111/j.16000854.2011.01168.x

Ban N, Nissen P, Hansen J, Moore PB, and Steitz TA. 2000. The complete atomic structure of the large ribosomal subunit at 2.4 A resolution. Science 289:905-920.

Bell SD, and Jackson SP. 2000. Mechanism of autoregulation by an archaeal transcriptional repressor. J Biol Chem 275:31624-31629. 10.1074/jbc.M005422200

Beyer KS, Beauchamp RL, Lee MF, Gusella JF, Naar AM, and Ramesh V. 2007. Mediator subunit MED28 (Magicin) is a repressor of smooth muscle cell differentiation. J Biol Chem 282:32152-32157.

Blumenthal T. 2012. Trans-splicing and operons in C. elegans. WormBook:1-11.

Bosher JM, Dufourcq P, Sookhareea S, and Labouesse M. 1999. RNA interference can target premRNA: consequences for gene expression in a Caenorhabditis elegans operon. Genetics 153:1245-1256.

Bourbon H-M, Aguilera A, Ansari AZ, Asturias FJ, Berk AJ, Bjorklund S, Blackwell TK, Borggrefe T, Carey M, Carlson M, Conaway JW, Conaway RC, Emmons SW, Fondell JD, Freedman LP, Fukasawa T, Gustafsson CM, Han M, He X, Herman PK, Hinnebusch AG, Holmberg S, Holstege FC, Jaehning JA, Kim Y-J, Kuras L, Leutz A, Lis JT, Meisterernest M, Naar AM, Nasmyth K, Parvin JD, Ptashne M, Reinberg D, Ronne H, Sadowski I, Sakurai H, Sipiczki M, Sternberg PW, Stillman DJ, Strich R, Struhl K, Svejstrup JQ, Tuck S, Winston F, Roeder RG, and Kornberg RD. 2004. A unified nomenclature for protein subunits of mediator complexes linking transcriptional regulators to RNA polymerase II. Molecular cell 14:553-557.

Bourbon HM. 2008. Comparative genomics supports a deep evolutionary origin for the large, fourmodule transcriptional mediator complex. Nucleic Acids Res 36:3993-4008. 10.1093/nar/gkn349

Brenner S. 1974. The genetics of Caenorhabditis elegans. Genetics 77:71-94.

Brzovic PS, Heikaus CC, Kisselev L, Vernon R, Herbig E, Pacheco D, Warfield L, Littlefield P, Baker D, Klevit RE, and Hahn S. 2011. The acidic transcription activator Gen4 binds the 
702

703

704

705

706

707

708

709

710

711

712

713

714

715

716

717

718

719

720

721

722

723

724

725

726

727

728

729

730

731

732

733

734

735

736

737

738

739

740

741

742

743

744

745

mediator subunit Gal11/Med15 using a simple protein interface forming a fuzzy complex. Mol Cell 44:942-953. 10.1016/j.molcel.2011.11.008

Burton ZF, Opron K, Wei G, and Geiger JH. 2016. A model for genesis of transcription systems. Transcription 7:1-13. 10.1080/21541264.2015.1128518

Cevher MA, Shi Y, Li D, Chait BT, Malik S, and Roeder RG. 2014. Reconstitution of active human core Mediator complex reveals a critical role of the MED14 subunit. Nat Struct Mol Biol 21:1028-1034. 10.1038/nsmb.2914

Chughtai AA, Kassak F, Kostrouchova M, Novotny JP, Krause MW, Saudek V, Kostrouch Z, and Kostrouchova M. 2015. Perilipin-related protein regulates lipid metabolism in C. elegans. PeerJ 3:e1213. 10.7717/peerj.1213

Clamp M, Cuff J, Searle SM, and Barton GJ. 2004. The Jalview Java alignment editor. Bioinformatics 20:426-427.

Cuff JA, and Barton GJ. 2000. Application of multiple sequence alignment profiles to improve protein secondary structure prediction. Proteins 40:502-511.

D'Alessio JA, Ng R, Willenbring H, and Tjian R. 2011. Core promoter recognition complex changes accompany liver development. Proc Natl Acad Sci U S A 108:3906-3911. 10.1073/pnas. 1100640108

Deato MDE, Marr MT, Sottero T, Inouye C, Hu P, and Tjian R. 2008. MyoD targets TAF3/TRF3 to activate myogenin transcription. Molecular cell 32:96-105.

Dettmann A, Jaschke Y, Triebel I, Bogs J, Schroder I, and Schuller H-J. 2010. Mediator subunits and histone methyltransferase Set2 contribute to Ino2-dependent transcriptional activation of phospholipid biosynthesis in the yeast Saccharomyces cerevisiae. Molecular genetics and genomics : $M G G$ 283:211-221.

Di Tommaso P, Moretti S, Xenarios I, Orobitg M, Montanyola A, Chang JM, Taly JF, and Notredame C. 2011. T-Coffee: a web server for the multiple sequence alignment of protein and RNA sequences using structural information and homology extension. Nucleic Acids Res 39:W13-17.

Diaz JJ, Dodon MD, Schaerer-Uthurralt N, Simonin D, Kindbeiter K, Gazzolo L, and Madjar JJ. 1996. Post-transcriptional transactivation of human retroviral envelope glycoprotein expression by herpes simplex virus Us11 protein. Nature 379:273-277. 10.1038/379273a0

Diaz JJ, Simonin D, Masse T, Deviller P, Kindbeiter K, Denoroy L, and Madjar JJ. 1993. The herpes simplex virus type 1 US11 gene product is a phosphorylated protein found to be non-specifically associated with both ribosomal subunits. J Gen Virol 74 ( Pt 3):397-406. 10.1099/0022-1317-74-3-397

Dickinson DJ, and Goldstein B. 2016. CRISPR-Based Methods for Caenorhabditis elegans Genome Engineering. Genetics 202:885-901. 10.1534/genetics.115.182162

Dickinson DJ, Pani AM, Heppert JK, Higgins CD, and Goldstein B. 2015. Streamlined Genome Engineering with a Self-Excising Drug Selection Cassette. Genetics 200:1035-1049. 10.1534/genetics.115.178335

Dickinson DJ, Ward JD, Reiner DJ, and Goldstein B. 2013. Engineering the Caenorhabditis elegans genome using Cas9-triggered homologous recombination. Nat Methods 10:10281034. 10.1038/nmeth.2641

Ecsedi M, Rausch M, and Grosshans H. 2015. The let-7 microRNA directs vulval development through a single target. Dev Cell 32:335-344. 10.1016/j.devcel.2014.12.018 
746

747

748

749

750

751

752

753

754

755

756

757

758

759

760

761

762

763

764

765

766

767

768

769

770

771

772

773

774

775

776

777

778

779

780

781

782

783

784

785

786

787

788

789

790

Eppig JT, Blake JA, Bult CJ, Kadin JA, Richardson JE, and Mouse Genome Database G. 2015. The Mouse Genome Database (MGD): facilitating mouse as a model for human biology and disease. Nucleic Acids Res 43:D726-736. 10.1093/nar/gku967

Frand AR, Russel S, and Ruvkun G. 2005. Functional genomic analysis of C. elegans molting. PLoS Biol 3:e312.

Gan L, Zheng W, Chabot JG, Unterman TG, and Quirion R. 2005. Nuclear/cytoplasmic shuttling of the transcription factor FoxO1 is regulated by neurotrophic factors. $J$ Neurochem 93:1209-1219.

George AA, Schiltz RL, and Hager GL. 2009. Dynamic access of the glucocorticoid receptor to response elements in chromatin. Int $J$ Biochem Cell Biol 41:214-224. 10.1016/j.biocel.2008.09.019

Grants JM, Goh GY, and Taubert S. 2015. The Mediator complex of Caenorhabditis elegans: insights into the developmental and physiological roles of a conserved transcriptional coregulator. Nucleic Acids Res 43:2442-2453.

Grants JM, Ying LT, Yoda A, You CC, Okano H, Sawa H, and Taubert S. 2016. The Mediator Kinase Module Restrains Epidermal Growth Factor Receptor Signaling and Represses Vulval Cell Fate Specification in Caenorhabditis elegans. Genetics 202:583-599. 10.1534/genetics.115.180265

Hirata A, and Murakami KS. 2009. Archaeal RNA polymerase. Curr Opin Struct Biol 19:724-731. 10.1016/j.sbi.2009.10.006

Hobert O. 2002. PCR fusion-based approach to create reporter gene constructs for expression analysis in transgenic C. elegans. Biotechniques 32:728-730.

Holstege FC, Jennings EG, Wyrick JJ, Lee TI, Hengartner CJ, Green MR, Golub TR, Lander ES, and Young RA. 1998. Dissecting the regulatory circuitry of a eukaryotic genome. Cell 95:717-728.

Huang CY, Chou YH, Hsieh NT, Chen HH, and Lee MF. 2012. MED28 regulates MEK1dependent cellular migration in human breast cancer cells. J Cell Physiol 227:3820-3827. 10.1002/jcp. 24093

Huang CY, Hsieh NT, Li CI, Weng YT, Liu HS, and Lee MF. 2017. MED28 Regulates EpithelialMesenchymal Transition Through NFkappaB in Human Breast Cancer Cells. J Cell Physiol 232:1337-1345. 10.1002/jcp.25610

Jones DT. 1999. Protein secondary structure prediction based on position-specific scoring matrices. J Mol Biol 292:195-202.

Kamath RS, and Ahringer J. 2003. Genome-wide RNAi screening in Caenorhabditis elegans. Methods 30:313-321.

Kim TW, Kwon YJ, Kim JM, Song YH, Kim SN, and Kim YJ. 2004. MED16 and MED23 of Mediator are coactivators of lipopolysaccharide- and heat-shock-induced transcriptional activators. Proc Natl Acad Sci U S A 101:12153-12158.

Kostrouch D, Kostrouchova M, Yilma P, Chughtai AA, Novotny JP, Novak P, Kostrouchova V, and Kostrouch Z. 2014. SKIP and BIR-1/Survivin have potential to integrate proteome status with gene expression. J Proteomics.

Krebs P, Fan W, Chen YH, Tobita K, Downes MR, Wood MR, Sun L, Li X, Xia Y, Ding N, Spaeth JM, Moresco EM, Boyer TG, Lo CW, Yen J, Evans RM, and Beutler B. 2011. Lethal mitochondrial cardiomyopathy in a hypomorphic Med30 mouse mutant is ameliorated by ketogenic diet. Proc Natl Acad Sci U S A 108:19678-19682. 10.1073/pnas.1117835108 
791

792

793

794

795

796

797

798

799

800

801

802

803

804

805

806

807

808

809

810

811

812

813

814

815

816

817

818

819

820

821

822

823

824

825

826

827

828

829

830

831

832

833

834

835

836

Kulak NA, Pichler G, Paron I, Nagaraj N, and Mann M. 2014. Minimal, encapsulated proteomicsample processing applied to copy-number estimation in eukaryotic cells. Nat Methods 11:319-324.

Lee MF, Beauchamp RL, Beyer KS, Gusella JF, and Ramesh V. 2006. Magicin associates with the Src-family kinases and is phosphorylated upon CD3 stimulation. Biochem Biophys Res Commun 348:826-831. 10.1016/j.bbrc.2006.07.126

Lee YJ, Han ME, Baek SJ, Kim SY, and Oh SO. 2015. MED30 Regulates the Proliferation and Motility of Gastric Cancer Cells. PLoS One 10:e0130826. 10.1371/journal.pone.0130826

Li L, Walsh RM, Wagh V, James MF, Beauchamp RL, Chang YS, Gusella JF, Hochedlinger K, and Ramesh V. 2015. Mediator Subunit Med28 Is Essential for Mouse Peri-Implantation Development and Pluripotency. PLoS One 10:e140192.

Liu C, Zhang L, Shao ZM, Beatty P, Sartippour M, Lane TF, Barsky SH, Livingston E, and Nguyen M. 2002. Identification of a novel endothelial-derived gene EG-1. Biochem Biophys Res Commun 290:602-612. 10.1006/bbrc.2001.6119

Lu M, Zhang L, Sartippour MR, Norris AJ, and Brooks MN. 2006. EG-1 interacts with c-Src and activates its signaling pathway. Int J Oncol 29:1013-1018.

Ly K, Reid SJ, and Snell RG. 2015. Rapid RNA analysis of individual Caenorhabditis elegans. MethodsX 2:59-63. 10.1016/j.mex.2015.02.002

Malik S, Guermah M, Yuan CX, Wu W, Yamamura S, and Roeder RG. 2004. Structural and functional organization of TRAP220, the TRAP/mediator subunit that is targeted by nuclear receptors. Mol Cell Biol 24:8244-8254. 10.1128/MCB.24.18.8244-8254.2004

Marcel V, Ghayad SE, Belin S, Therizols G, Morel AP, Solano-Gonzalez E, Vendrell JA, Hacot S, Mertani HC, Albaret MA, Bourdon JC, Jordan L, Thompson A, Tafer Y, Cong R, Bouvet P, Saurin JC, Catez F, Prats AC, Puisieux A, and Diaz JJ. 2013. p53 acts as a safeguard of translational control by regulating fibrillarin and rRNA methylation in cancer. Cancer Cell 24:318-330. 10.1016/j.ccr.2013.08.013

Matus DQ, Li XY, Durbin S, Agarwal D, Chi Q, Weiss SJ, and Sherwood DR. 2010. In vivo identification of regulators of cell invasion across basement membranes. Sci Signal 3:ra35. $10.1126 /$ scisignal.2000654

McClatchey AI, and Fehon RG. 2009. Merlin and the ERM proteins--regulators of receptor distribution and signaling at the cell cortex. Trends Cell Biol 19:198-206.

McClatchey AI, and Giovannini M. 2005. Membrane organization and tumorigenesis--the NF2 tumor suppressor, Merlin. Genes Dev 19:2265-2277.

McGuffin LJ, Bryson K, and Jones DT. 2000. The PSIPRED protein structure prediction server. Bioinformatics 16:404-405.

Mounsey A, Bauer P, and Hope IA. 2002. Evidence suggesting that a fifth of annotated Caenorhabditis elegans genes may be pseudogenes. Genome Res 12:770-775.

Nagulapalli M, Maji S, Dwivedi N, Dahiya P, and Thakur JK. 2016. Evolution of disorder in Mediator complex and its functional relevance. Nucleic Acids Res 44:1591-1612. $10.1093 / \mathrm{nar} / \mathrm{gkv} 1135$

Nguyen-Lefebvre AT, Leprun G, Morin V, Vinuelas J, Coute Y, Madjar JJ, Gandrillon O, and Gonin-Giraud S. 2014. V-erbA generates ribosomes devoid of RPL11 and regulates translational activity in avian erythroid progenitors. Oncogene 33:1581-1589. 10.1038/onc.2013.93

Notredame C, Higgins DG, and Heringa J. 2000. T-Coffee: A novel method for fast and accurate multiple sequence alignment. $J$ Mol Biol 302:205-217. 
837 Orell A, Peeters E, Vassen V, Jachlewski S, Schalles S, Siebers B, and Albers SV. 2013. Lrs14

838

839

840

841

842

843

844

845

846

847

848

849

850

851

852

853

854

855

856

857

858

859

860

861

862

863

864

865

866

867

868

869

870

871

872

873

874

875

876

877

878

879

880

881

882 transcriptional regulators influence biofilm formation and cell motility of Crenarchaea. ISME J 7:1886-1898. 10.1038/ismej.2013.68

Palmer E, and Freeman T. 2004. Investigation into the use of C- and N-terminal GFP fusion proteins for subcellular localization studies using reverse transfection microarrays. Comp Funct Genomics 5:342-353. 10.1002/cfg.405

Paoletti AC, Parmely TJ, Tomomori-Sato C, Sato S, Zhu D, Conaway RC, Conaway JW, Florens L, and Washburn MP. 2006. Quantitative proteomic analysis of distinct mammalian Mediator complexes using normalized spectral abundance factors. Proc Natl Acad Sci U S A 103:18928-18933. 10.1073/pnas.0606379103

Pei J, and Grishin NV. 2007. PROMALS: towards accurate multiple sequence alignments of distantly related proteins. Bioinformatics 23:802-808.

Pei J, Kim BH, and Grishin NV. 2008. PROMALS3D: a tool for multiple protein sequence and structure alignments. Nucleic Acids Res 36:2295-2300.

Pei J, Kim BH, Tang M, and Grishin NV. 2007. PROMALS web server for accurate multiple protein sequence alignments. Nucleic Acids Res 35:W649-652.

Poss ZC, Ebmeier CC, and Taatjes DJ. 2013. The Mediator complex and transcription regulation. Crit Rev Biochem Mol Biol 48:575-608. 10.3109/10409238.2013.840259

Qian W, and Zhang J. 2008. Evolutionary dynamics of nematode operons: easy come, slow go. Genome Res 18:412-421.

Rachez C, and Freedman LP. 2001. Mediator complexes and transcription. Curr Opin Cell Biol 13:274-280.

Remmert M, Biegert A, Hauser A, and Soding J. 2011. HHblits: lightning-fast iterative protein sequence searching by HMM-HMM alignment. Nat Methods 9:173-175.

Sato S, Tomomori-Sato C, Parmely TJ, Florens L, Zybailov B, Swanson SK, Banks CA, Jin J, Cai Y, Washburn MP, Conaway JW, and Conaway RC. 2004. A set of consensus mammalian mediator subunits identified by multidimensional protein identification technology. Mol Cell 14:685-691.

Schluenzen F, Tocilj A, Zarivach R, Harms J, Gluehmann M, Janell D, Bashan A, Bartels H, Agmon I, Franceschi F, and Yonath A. 2000. Structure of functionally activated small ribosomal subunit at 3.3 angstroms resolution. Cell 102:615-623.

Schneider CA, Rasband WS, and Eliceiri KW. 2012. NIH Image to ImageJ: 25 years of image analysis. Nat Methods 9:671-675.

Simeckova K, Brozova E, Vohanka J, Pohludka M, Kostrouch Z, Krause MW, Rall JE, and Kostrouchova M. 2007. Supplementary nuclear receptor NHR-60 is required for normal embryonic and early larval development of Caenorhabditis elegans. Folia Biol (Praha) 53:85-96.

Simmer F, Moorman C, van der Linden AM, Kuijk E, van den Berghe PV, Kamath RS, Fraser AG, Ahringer J, and Plasterk RH. 2003. Genome-wide RNAi of C. elegans using the hypersensitive rrf-3 strain reveals novel gene functions. PLoS Biol 1:E12.

Soding J, Biegert A, and Lupas AN. 2005. The HHpred interactive server for protein homology detection and structure prediction. Nucleic Acids Res 33:W244-248.

Sonnichsen B, Koski LB, Walsh A, Marschall P, Neumann B, Brehm M, Alleaume AM, Artelt J, Bettencourt P, Cassin E, Hewitson M, Holz C, Khan M, Lazik S, Martin C, Nitzsche B, Ruer M, Stamford J, Winzi M, Heinkel R, Roder M, Finell J, Hantsch H, Jones SJ, Jones M, Piano F, Gunsalus KC, Oegema K, Gonczy P, Coulson A, Hyman AA, and Echeverri 
883

884

885

886

887

888

889

890

891

892

893

894

895

896

897

898

899

900

901

902

903

904

905

906

907

908

909

910

911

912

913

914

915

916

917

918

919

920

921

922

923

924

925

926

927
CJ. 2005. Full-genome RNAi profiling of early embryogenesis in Caenorhabditis elegans. Nature 434:462-469.

Taatjes DJ, and Tjian R. 2004. Structure and function of CRSP/Med2; a promoter-selective transcriptional coactivator complex. Mol Cell 14:675-683. 10.1016/j.molcel.2004.05.014

Tabara H, Sarkissian M, Kelly WG, Fleenor J, Grishok A, Timmons L, Fire A, and Mello CC. 1999. The rde-1 gene, RNA interference, and transposon silencing in C. elegans. Cell 99:123-132.

Thaw P, Sedelnikova SE, Muranova T, Wiese S, Ayora S, Alonso JC, Brinkman AB, Akerboom J, van der Oost J, and Rafferty JB. 2006. Structural insight into gene transcriptional regulation and effector binding by the Lrp/AsnC family. Nucleic Acids Res 34:1439-1449. 10.1093/nar/gk1009

Thompson CM, and Young RA. 1995. General requirement for RNA polymerase II holoenzymes in vivo. Proc Natl Acad Sci U S A 92:4587-4590.

Timmons L, Court DL, and Fire A. 2001. Ingestion of bacterially expressed dsRNAs can produce specific and potent genetic interference in Caenorhabditis elegans. Gene 263:103-112.

Uhlen M, Fagerberg L, Hallstrom BM, Lindskog C, Oksvold P, Mardinoglu A, Sivertsson A, Kampf C, Sjostedt E, Asplund A, Olsson I, Edlund K, Lundberg E, Navani S, Szigyarto CA, Odeberg J, Djureinovic D, Takanen JO, Hober S, Alm T, Edqvist PH, Berling H, Tegel H, Mulder J, Rockberg J, Nilsson P, Schwenk JM, Hamsten M, von Feilitzen K, Forsberg M, Persson L, Johansson F, Zwahlen M, von Heijne G, Nielsen J, and Ponten F. 2015. Proteomics. Tissue-based map of the human proteome. Science 347:1260419. 10.1126/science.1260419

Uwamahoro N, Qu Y, Jelicic B, Lo TL, Beaurepaire C, Bantun F, Quenault T, Boag PR, Ramm G, Callaghan J, Beilharz TH, Nantel A, Peleg AY, and Traven A. 2012. The functions of Mediator in Candida albicans support a role in shaping species-specific gene expression. PLoS Genet 8:e1002613. 10.1371/journal.pgen.1002613

Vohanka J, Simeckova K, Machalova E, Behensky F, Krause MW, Kostrouch Z, and Kostrouchova M. 2010. Diversification of fasting regulated transcription in a cluster of duplicated nuclear hormone receptors in C. elegans. Gene Expr Patterns 10:227-236.

Wang W, Li X, Lee M, Jun S, Aziz KE, Feng L, Tran MK, Li N, McCrea PD, Park JI, and Chen J. 2015. FOXKs promote Wnt/beta-catenin signaling by translocating DVL into the nucleus. Dev Cell 32:707-718.

Ward JD. 2015. Rapid and precise engineering of the Caenorhabditis elegans genome with lethal mutation co-conversion and inactivation of NHEJ repair. Genetics 199:363-377. 10.1534/genetics.114.172361

Warfield L, Tuttle LM, Pacheco D, Klevit RE, and Hahn S. 2014. A sequence-specific transcription activator motif and powerful synthetic variants that bind Mediator using a fuzzy protein interface. Proc Natl Acad Sci $U$ S A 111:E3506-3513. 10.1073/pnas.1412088111

Wiederhold T, Lee MF, James M, Neujahr R, Smith N, Murthy A, Hartwig J, Gusella JF, and Ramesh V. 2004. Magicin, a novel cytoskeletal protein associates with the NF2 tumor suppressor merlin and Grb2. Oncogene 23:8815-8825.

Wimberly BT, Brodersen DE, Clemons WM, Jr., Morgan-Warren RJ, Carter AP, Vonrhein C, Hartsch T, and Ramakrishnan V. 2000. Structure of the 30S ribosomal subunit. Nature 407:327-339. 10.1038/35030006 
928 Zhu X, Chen L, Carlsten JO, Liu Q, Yang J, Liu B, and Gustafsson CM. 2015. Mediator tail 929 subunits can form amyloid-like aggregates in vivo and affect stress response in yeast. Nucleic Acids Res 43:7306-7314. 10.1093/nar/gkv629

931 Zima V, Sebkova K, Simeckova K, Dvorak T, Saudek V, and Kostrouchova M. 2015. Prorenin

932

933 Receptor Homologue VHA-20 is Critical for Intestinal pH Regulation, Ion and Water

934 Management and Larval Development in C. elegans. Folia Biol (Praha) 61:168-177. 


\section{Figure 1}

A multiple sequence alignment of selected metazoan homologues of MED28 compared with F28F8.5.

Aligned with PROMALS (http://prodata.swmed.edu/promals/promals.php), variable C- and Ntermini not shown, amino acid residue types colored according to Clustal scheme in Jalview, red bars indicate consensus positions of predicted $\alpha$-helices. Sequences from top to bottom (organism, identifier): Caenorhabditis elegans, 018692; Trichinella spiralis, E5RZQ1;

Wuchereria bancrofti, EJW84794.1; Pristionchus pacificus, translated contig of CN657719.1 FG102945.1 CN657262.1 CN656622.1; Ancylostoma ceylanicum, A0A016SKV7; Globodera pallida, translated CV578368.1; Panagrolaimus davidi, translated JZ658977.1; Ixodes scapularis, B7PAW5; Drosophila melanogaster, MED28_DROME; Homo sapiens, MED28_HUMAN. Readers with specific color preferences may download the compared sequences from (Supplementary File S1) and create the Clustal scheme with different color specifications using the Jalview program ( http://www.jalview.org/ )

\footnotetext{
C.elegans

T.spiralis

W.bancrofti

P.pacificus

A.ceylanicum

G.pallida

P.davidi

I.scapularis

D.melanogaster

H.sapiens $\alpha$-helix

C.elegans

T.spiralis

W.bancrofti

P.pacificus

A.ceylanicum

G.pallida

P.davidi

I.scapularis

D.melanogaster

$H$. sapiens
$\alpha-$ helix

81 PTYLGDA I DS LMMHWCQLLTNVSVKAPVPPPSTLNHVKEVAEVCSKHFRDASVDVNNE 138 3 - EYNGDV INNFRQAVKSCLTLLSVPVKSRH I - EADE I KTTAEVATHRL I EAARRSERH 58 51 DT PLGQAVTNLHGSWAQL I SDLSARTGYLPP-TLEH I KEVAECAVRQLKDSCHDLTRE 107 56 RS ALGDAVDALL LNWS Q I MSNTGTKYPS VPP - S LDHVKEVAA I VVQGFRDACGDLNAE 112 50 RTPLGDA I DS LLVRWAQL LSNVSSRPPVPAPST I DHVKEVVE I SMYHFRDSCLDVCSE 107 47 DS ALGTALKNMVMQWNS L LSQVVTEVDHPQP - I LEH I KETAEFS VKQFRDACLAMNSE 103 142 ATPLMLCVDRLYQSYNNL I LDFFPESG I ALP-PQSDI KESAEFNVKSFRDACQELTAE 198 4 - - S SQ I VDDFENSFQACLAAVTNPDYFYVR - DSEEVKTGVEQT I QR F LDVAKQMECF 57 5 ESGGGNLMDEFEEAFQSCLLTLTKQEPNSGT-NKEE I DLEVQKTTNRF I DVARQMEAF 61 38 R PSS STLVDELESSFEACFASLVSQDYVNGT-DQEE I RTGVDQCIQKFLDIARQTECF 94

139 FTRLGVQWEMEQPYSQYA I EEENLDEA I ERQET I I AAAREMLNSR I Q- I YNEAHPNAG 195 59 FVRLYALFS AYCPEEVLKEE I NEMKQE I ERKKNML L KHEEKM I AWEQ - I LSEAETPLT 115 108 FAR VGLEWR LTHPDEALAEDLADYDQAMLRQESLLERAAS I VERRLS - DLGAEKNSQG 164 113 FAKVALEWE LENGRAAEDERVAALKGS I SRQVTLLARAQAALDLRTE - DYFCSSLDAA 169 108 F TK I DLQWQLDHPEEVYEDEMKGLDDAL I RQETLLARAHG I LDRRCK - EFFG- - - - 158 104 LTR I SMDWQLNFPDEMVKQE I VEYENS I RRQEDLLTK I RQKLDEE I - - -SSGENSNFG 158 199 FTR S AVEWQLMNPQEYYADE I KDLDKA I ARQTE I QKRVEGK I NSE INKS LNGD - - - 251 58 F LQKRLVLSAQKPEQ I VMEDNTELKNE LARKEQL LQKYHEK I HFWQS - L LNDTNNAPG 114 62 F LQKRFLVSTLKPYML I KDENQDLS I E I QRKEAL LQKHYNRLE EWKA - CLSD I QQGVH 118 95 F LQKRLQLSVQKPEQV IKEDVSELRNELQRKDALVQKHLTKLRHWQQ-VLEDINVQHK 151
} 


\section{Figure 2}

Expression pattern of GFP::F28F8.5 in homozygous animals with edited F28F8.5 gene.

GFP tagged to F28F8.5 at its N-terminus using CRISPR/Cas9 technology visualized the expression of F28F8.5 in the gonads (Panels B and D, arrows) in mitotic nuclei and continues throughout the embryonic development (Panels F, H, J and L). The wide and likely ubiquitous expression of GFP::F28F8.5 continues during larval stages (larvae L3 and L4 are shown in panels $\mathrm{M}, \mathrm{N}$ and $\mathrm{O}, \mathrm{P}$, respectively) as well as in adults (panels $\mathrm{Q}$ and $\mathrm{R}$ ). Expression of the edited gene in the nuclei of the developing vulva is indicated by the arrows in panels $M$ and N. Panels A, C, E, G, I, K, M, O and Q show larvae in Nomarski optics and panels B, D, F, H, J, $\mathrm{L}, \mathrm{N}, \mathrm{P}$ and $\mathrm{R}$ in GFP fluorescence. Bars represent $50 \mu \mathrm{m}$. 

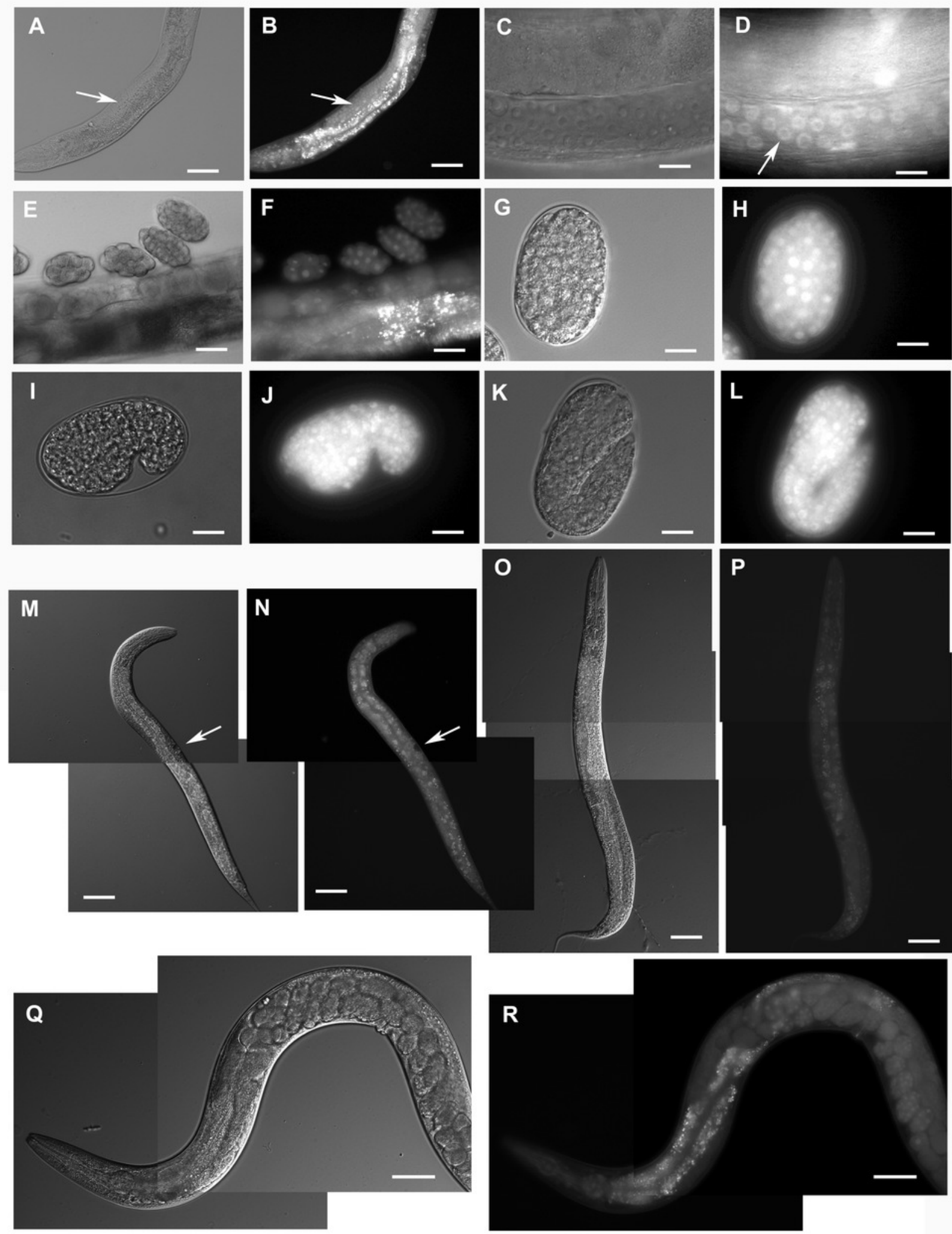

P

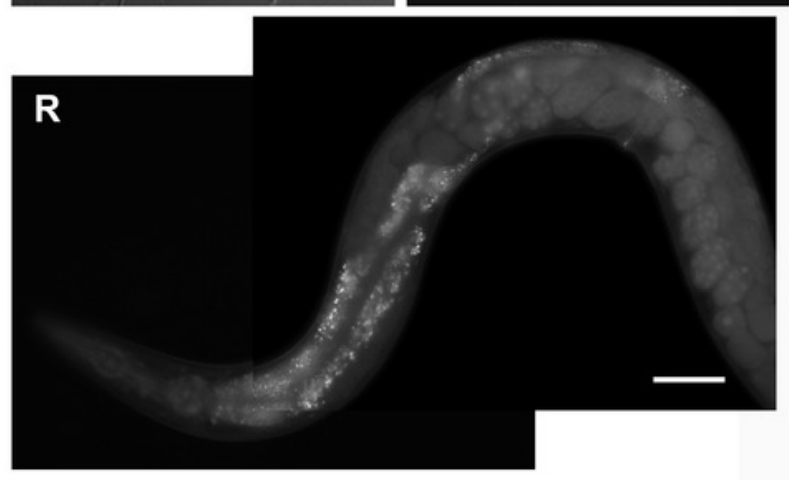




\section{Figure 3}

Analysis of GFP::F28F8.5 expression in homozygous animals with edited F28F8.5 gene by confocal microscopy and fluorescence lifetime imaging microscopy (FLIM).

All confocal images of GFP fluorescence are recorded in Channel 1 (495 to $525 \mathrm{~nm}$ ). FLIM images (panels $A$ to $E, H, J, L, M, O$ to $S, U$ and $V$ ) are calculated from merged recordings in Channel 1 and Channel 2 (525 nm to $585 \mathrm{~nm}$ ). Panels F, K, and N are images in Nomarski optics at same optical focus as in corresponding confocal images of GFP fluorescence (panels $G, I, L, O)$. Panels A and B show control images of WT embryos in bean and comma stages, respectively. No specific signal is detected in control embryos by FLIM. Panels $C$ shows an embryo in bean stage expressing GFP::F28F8.5 from the edited gene. Two focal planes of an embryo expressing GFP::F28F8.5 in two fold stage are shown in panels D and E. FLIM detects GFP::F28F8.5 in most or all nuclei of developing embryos. Panels F to J show the distal part of a young adult control hermaphrodite animal and a control embryo in late bean stage. FLIM images in panels $\mathrm{H}$ and J show mostly short life-time fluorescence in the cytoplasm of embryonic cells as well as cells and subcellular structures in the adult control animal (visualized by blue color). Arrowheads pointing at the embryo in panels $\mathrm{G}$ and $\mathrm{H}$ indicate weak autofluorescence in the cytoplasm of embryonic cells. Arrows in panels $F, G$ and $H$ indicate the turn of gonad and arrowheads indicate nuclei of an enterocyte which is devoid of almost all fluorescence (panels $\mathrm{G}$ and $\mathrm{H}$ ). Panels $\mathrm{K}$ to $\mathrm{S}$ and $\mathrm{U}$ and $\mathrm{V}$ show animals with edited F28F8.5 ( $g f p:: F 28 F 8.5$ ). Panel M shows the distal part of an adult hermaphrodite animal expressing GFP::F28F8.5 from the edited gene at recording settings identical with that used in the control sample shown in panels A, B, H and J. FLIM analysis shows a long lifetime fluorescence in nuclei and in the cytoplasm of most cells that contrasts with the low level of fluorescence seen in the control sample. Arrowheads indicate nuclei of enterocytes in panels $\mathrm{L}$ and $\mathrm{M}$. Panels $\mathrm{N}$ to $\mathrm{V}$ show images of an adult animal and two $\mathrm{L} 1$ larvae with edited F28F8.5. Panels $\mathrm{P}$ to $\mathrm{S}$, and $\mathrm{U}$ show selected focal planes in FLIM. Panel $\mathrm{T}$ shows the 
calibration table for FLIM in the range of 1 to 3 ns used in all panels presenting FLIM analysis. Blue areas shown in FLIM pictures represent short life time fluorescence presumably corresponding to autofluorescence (blue arrows in panels $\mathrm{O}, \mathrm{S}$, and $\mathrm{U}$ ). Arrowheads in panels $\mathrm{O}, \mathrm{P}, \mathrm{R}$, and $\mathrm{S}$ indicate nuclei of enterocytes and in panel $\mathrm{U}$ nuclei of early embryos with long life-time fluorescence characteristic for GFP. Panel V shows the distal part of a male expressing GFP:F28F8.5 in male specific structures, in nuclei as well as in rays (marked by arrowheads) indicating that GFP::F28F8.5 is expressed not only in cell nuclei but also in the cytoplasmic structures. Bars represent $30 \mu \mathrm{m}$ in panels $\mathrm{A}$ to $\mathrm{E}$ and $50 \mu \mathrm{m}$ in panels $\mathrm{F}$ to $\mathrm{S}$ and $\mathrm{U}$ and $\mathrm{V}$. 

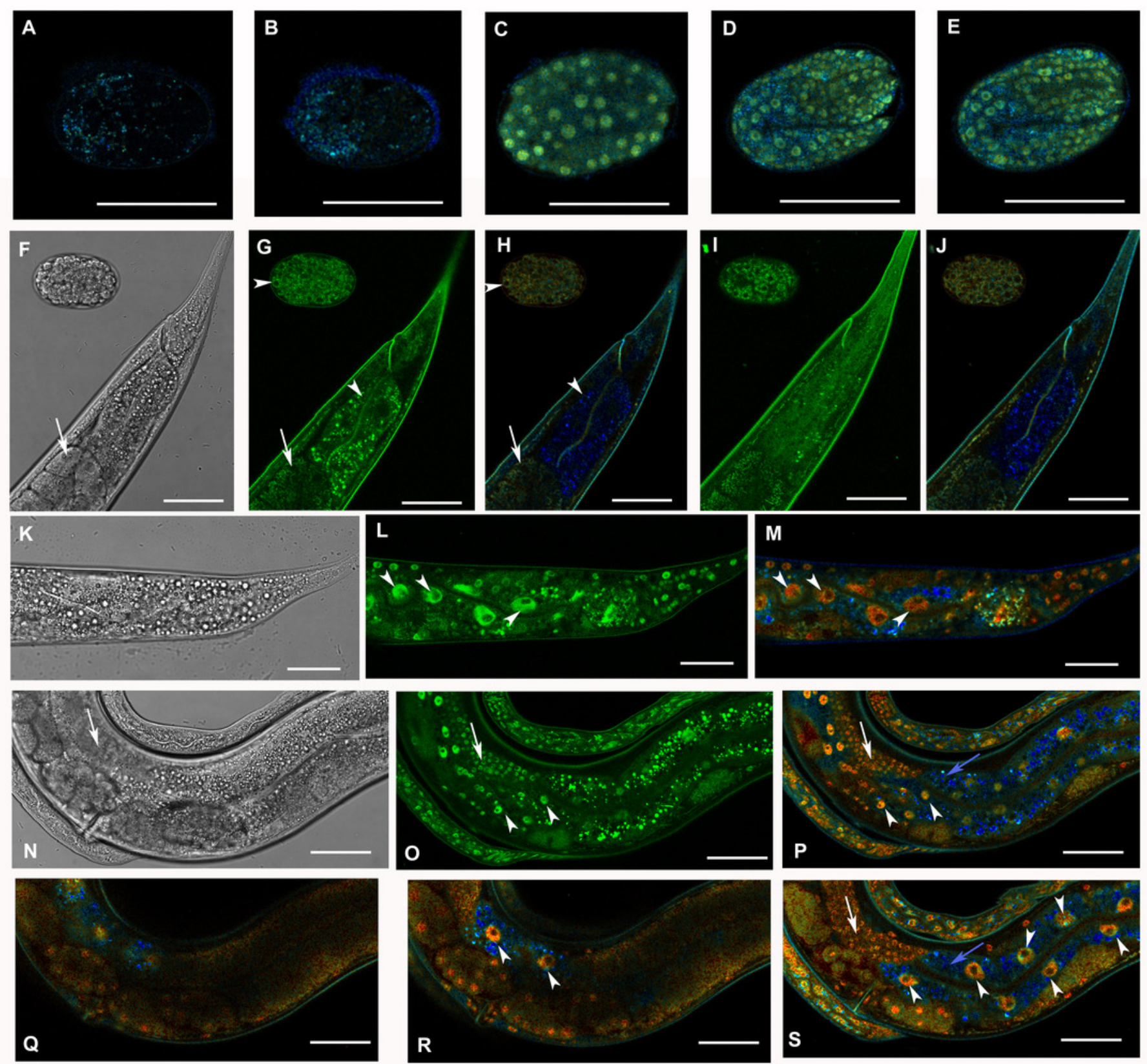

T
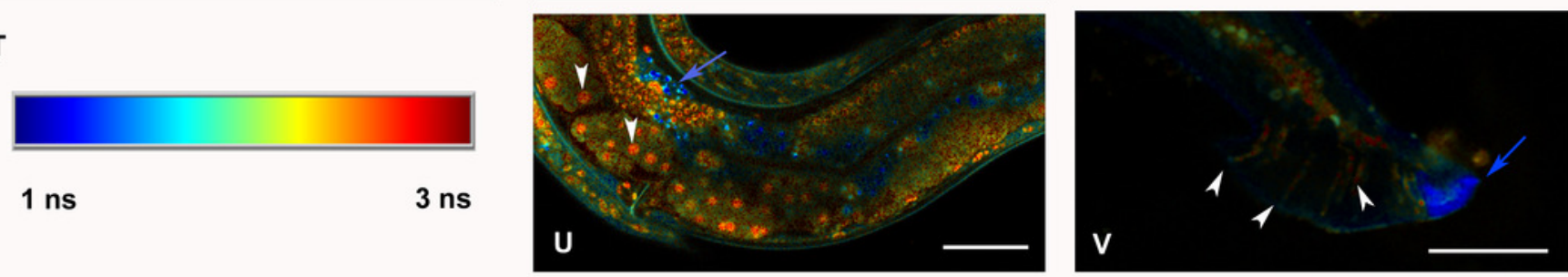


\section{Figure 4}

Down-regulation of $F 28 F 8.5$ by RNAi induces developmental defects.

Animals developed from parents injected with dsRNA specific for F28F8.5 show retention of normal and malformed embryos (panels $A$ and $K$, respectively), vacuoles (panels $A$ and $C$, arrows), herniation and burst through the vulva (panels B, C, I, and J, arrowheads) and defective development of the gonad (panels J and M). Panel $D$ shows a male nematode with defects of male specific structures - missing rays and fan and an abnormal distal part of the body (arrow). Panel E shows the magnified distal part of the male nematode in panel $D$ and the defective male specific structures (arrow). Panels $\mathrm{F}$ and $\mathrm{H}$ show $\mathrm{L} 3$ larvae that were found atrophic, with thin enterocytes (arrowheads) and a dilated gut lumen (arrows). The dumpy phenotype with masses of tissue and vacuoles (panel G, arrows) were also common in the progeny of microinjected parents. Other phenotypes seen included molting defects indicated by arrows in panel $L$ and cellular defects (indicated by arrowheads in panels $L$ and $M$ ). Animals treated by control RNAi were morphologically normal and representative images are shown in panels N to Q. Panel N shows a L2 larva, panel O shows a young L3 larva with developing germline (arrow). Panel P shows a young L4 Larva with developing vulva marked by an arrow. Panel Q shows a grossly normal adult hermaphrodite animal with few developing embryos and vulva (arrow). Panel $\mathrm{R}$ and $\mathrm{S}$ show the distal part of the body of a male animal with normal appearance of male specific structures. Arrow marks spicules (in panel R) and normal sensoric rays (in panel S). All images are in Nomarski optics. Bars represent $50 \mu \mathrm{m}$. 

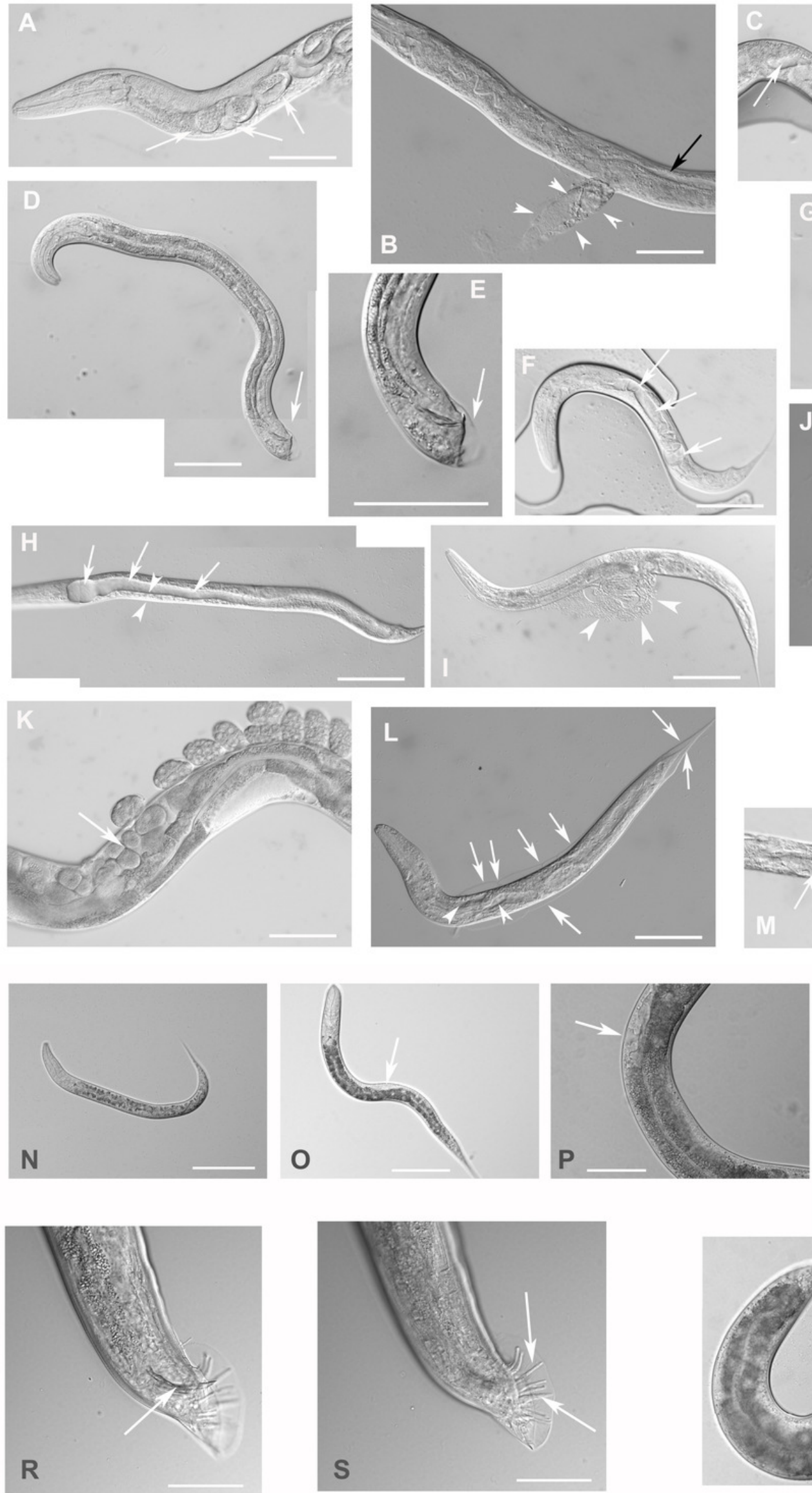

Peer) reviewing PDF | (2015:07:5837:1:0:NEW 23 Apr 2017)
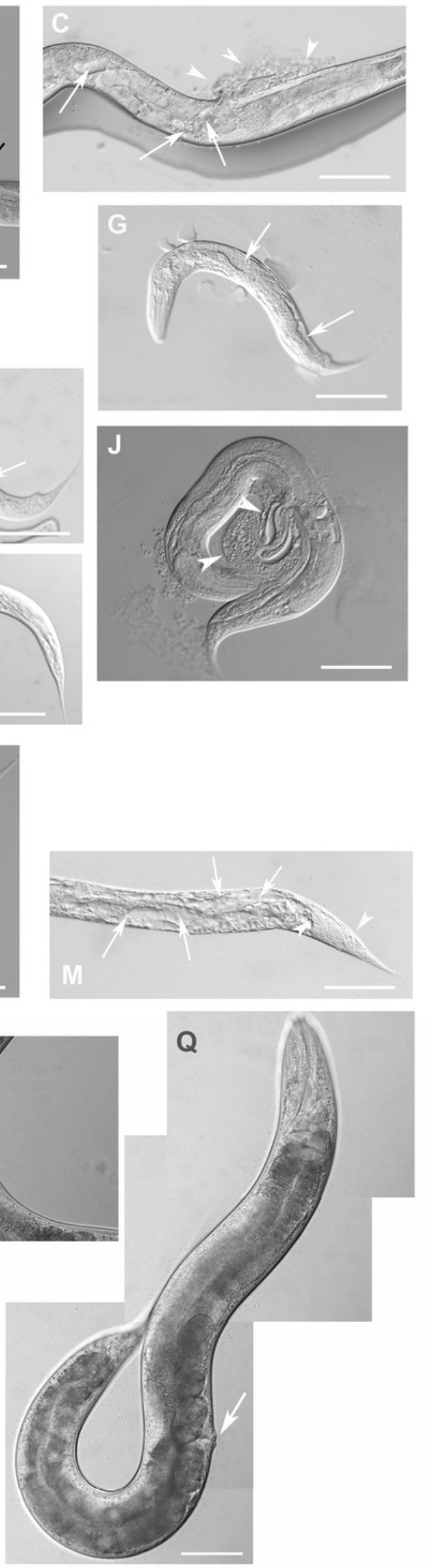


\section{Figure 5}

Disruption of F28F8.5 by CRISPR/Cas9 technique.

Animals with disrupted F28F8.5 on both alleles express GFP under the regulation of F28F8.5 promoter. Panels A to J show paired images of animals in Nomarski optics and in GFP fluorescence. Panels $A$ and $B$ show an adult hermaphrodite animal with diffuse fluorescence in cells in the head area including anterior arms of the excretory cell (arrowheads). Panels C and D show a malformed larva probably in L3 stage with a Dpy phenotype and diffuse fluorescence in a malformed gonad (arrows) and the intestine (arrowheads). Panels E and F show an adult hermaphrodite animal with diffuse fluorescence in gut, pharyngeal cells and severely malformed gonad containing irregular structures (arrows). Panels G, H, I and J show an adult animal with a malformed gonad, Pvul phenotype, dense gut and diffuse GFP fluorescence throughout the body. Panels $K$ and $L$ show the central part of the body of a hermaphrodite with the Pvul phenotype (arrowhead) and malformation of gonad (arrow). Panel $\mathrm{M}$ is composed of three consecutive images showing an adult hermaphrodite animal with severely malformed gonad (arrows), and missing uterus and spermaticae. The fluorescence images show that unlike GFP::F28F8.5, GFP alone localizes diffusely in the cytoplasm and is not found in nuclei. Bars represent $50 \mu \mathrm{m}$. 

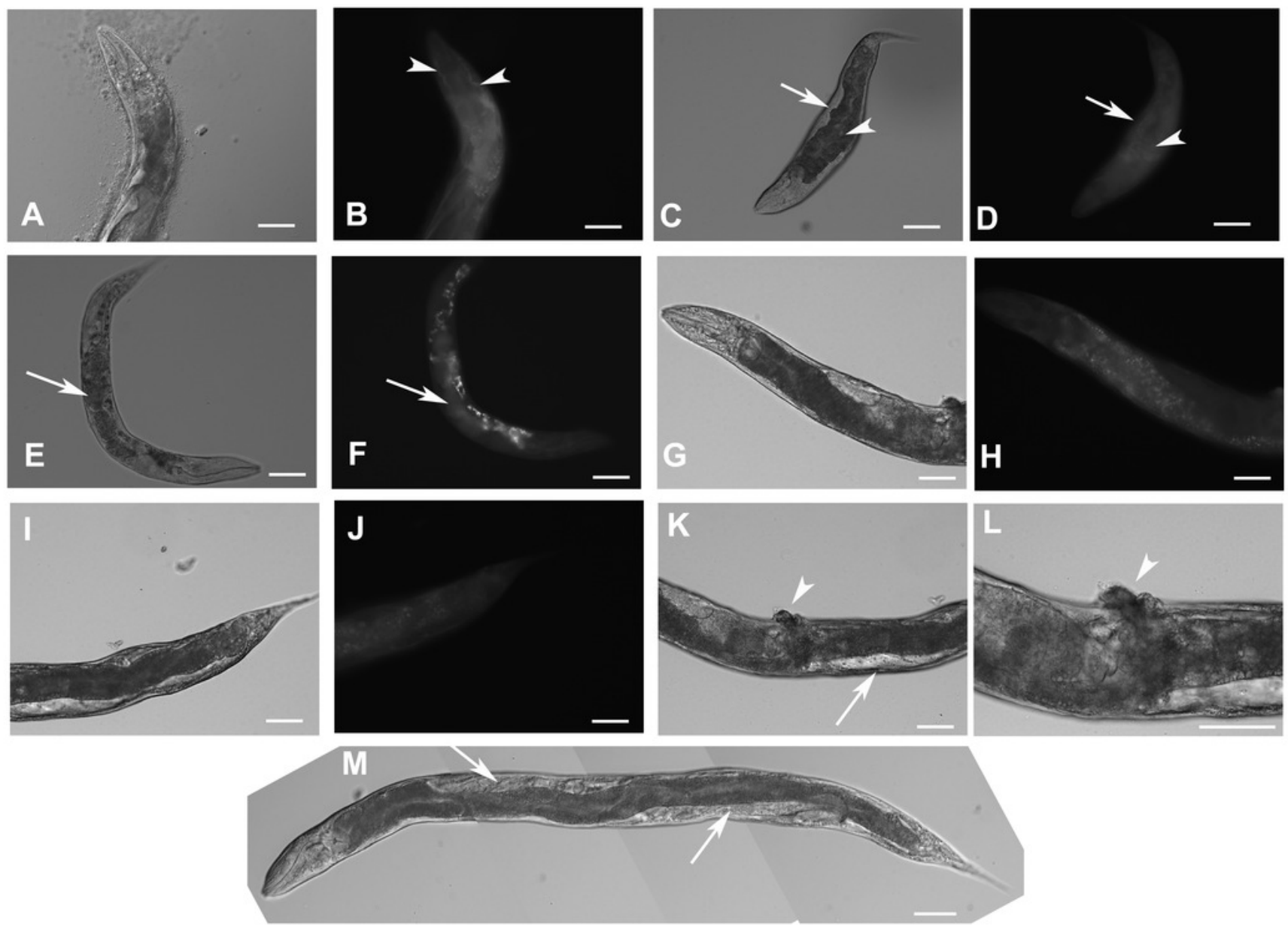


\section{Figure 6}

Heterozygous animals with one edited disrupted allele of F28F8.5 and one WT allele.

Heterozygous hermaphrodites carrying one edited allele of F28F8.5 and one WT had grossly normal appearance and could be recognized by rol phenotype, presence of embryos, weak mostly cytoplasmic GFP fluorescence and absence of nuclear localization of GFP fluorescence. Panels A (Nomarski optics) and B (GFP fluorescence) show an L3 larva with weak fluorescence (panel B, arrowhead points at the gonad and arrows point at the head and pharynx). Inlets show head area at higher magnification (rotated $90^{\circ}$ clockwise). Panels $C$ and $D$ show an adult hermaphrodite animal ( $C$ in Nomarski optics and D in GFP fluorescence) with weak cytoplasmic fluorescence in most cells. The arrowhead in panel D points at the nucleus of an enterocyte in focal plane that is devoid of GFP fluorescence. Arrows indicate two embryos with GFP fluorescence accumulated in nuclei which is most likely the result of spontaneous SEC self-excision. Panels $\mathrm{E}$ and $\mathrm{F}$ show an adult hermaphrodite in Nomarski optics (panel E) and GFP fluorescence (panel F). Arrows indicate the head area with diffuse intracellular fluorescence visible in panel F. Arrowheads point at two nuclei of enterocytes in focal plane that are also devoid of fluorescence. In contrast to the animal shown in panels $C$ and $D$, the animal shown in the panel $E$ and $F$ contains embryos that have mostly diffuse cytoplasmic expression of GFP. Bars represent $50 \mu \mathrm{m}$. 

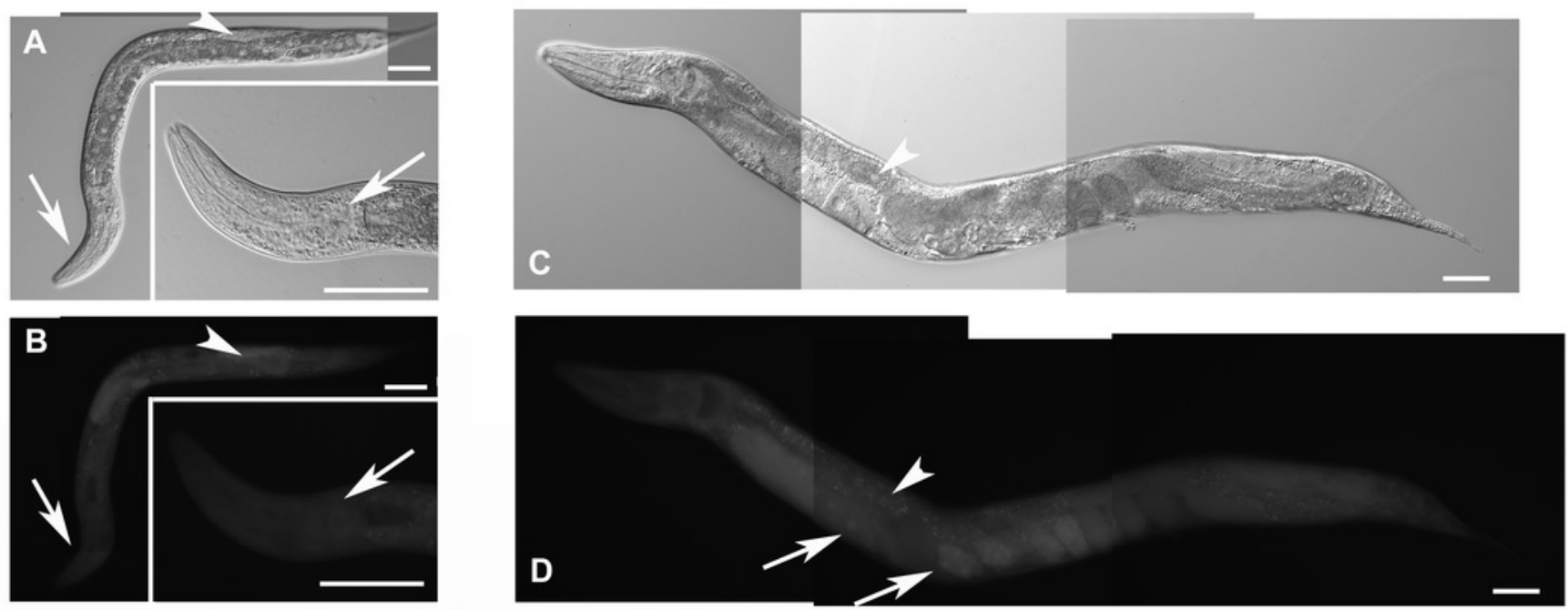

E

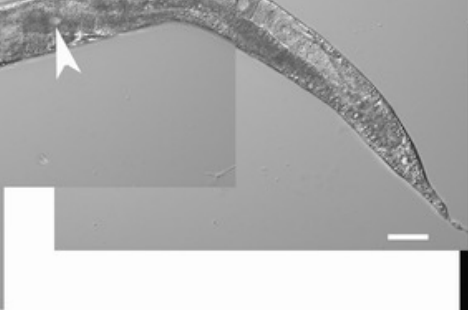

$\mathbf{F}$

1

A

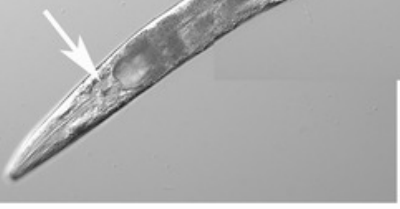

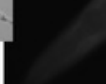




\section{Figure 7}

Binding of F28F8.5 to MDT-6 and MDT-30 in vitro.

GST-F28F8.5 or GST alone were expressed in bacteria and purified using glutathione-agarose beads that were incubated with ${ }^{35} \mathrm{~S}$-Methionine-MDT- 6 produced using rabbit reticulocyte lysate (A and $\mathrm{B}$ ) or $\mathrm{His}_{6}-\mathrm{MDT}-30-\mathrm{FLAG}$ expressed in bacteria and purified using a nickel column. Panels $\mathrm{A}$ and $\mathrm{C}$ show fractions bound to glutathione-agarose beads resolved by polyacrylamide gel electrophoresis and visualized by chemiluminescence (panel A). For quantification, dried gel areas corresponding to proteins detected by chemiluminescence were excised and the radioactively labeled MDT- 6 was determined using scintillation counter (panel B). Panels C and D show the interaction of FLAG-MDT-30 with GST-F28F8.5 or GST alone. FLAG-MDT-30 pulled-down by GST or GST-F28F8.5 was determined by Western blot using an anti-FLAG antibody (panel C) and by densitometry (panel D). Both assayed Mediator subunits, MDT-6 and MDT-30 bind GST-F28F8.5 preferentially in comparison to GST only.
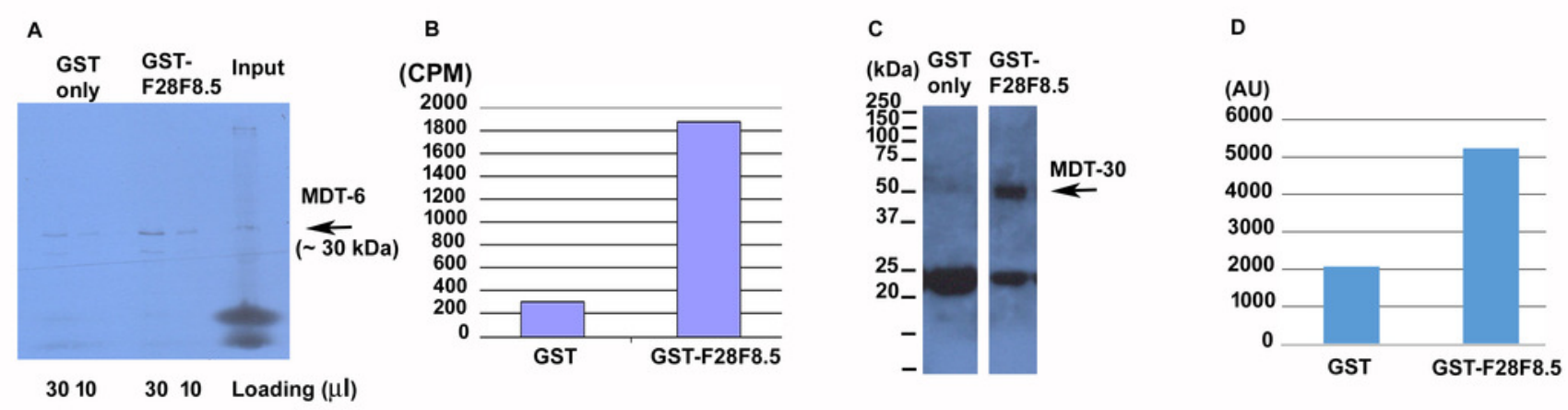